\title{
On the Potential of 25 Years (1991-2015) of Rawinsonde Measurements for Elucidating Climatological and Spatiotemporal Patterns of Afternoon Boundary Layer Depths over the Contiguous US
}

\author{
Temple R. Lee ${ }^{1}$ and Sandip Pal ${ }^{2}$ \\ ${ }^{1}$ Oak Ridge Associated Universities, Oak Ridge, TN, USA \\ ${ }^{2}$ Department of Meteorology and Atmospheric Science, Pennsylvania State University, University Park, PA, USA
}

Correspondence should be addressed to Sandip Pal; sup252@psu.edu

Received 24 November 2016; Revised 27 February 2017; Accepted 26 March 2017; Published 11 June 2017

Academic Editor: Anthony R. Lupo

Copyright (C) 2017 Temple R. Lee and Sandip Pal. This is an open access article distributed under the Creative Commons Attribution License, which permits unrestricted use, distribution, and reproduction in any medium, provided the original work is properly cited.

\begin{abstract}
The daytime planetary boundary layer (PBL) depth is an essential parameter in, for example, dispersion models and numerical weather prediction. We applied a recently developed technique to estimate afternoon PBL depths from 516,887 daily rawinsonde measurements obtained at 0000 UTC between 1 Jan 1991 and 31 Dec 2015 from 67 US sites. We discuss salient features in the PBL depth variability and examine the climatology of afternoon PBL depths as a function of geographical region and KöppenGeiger climate regime. Results indicated a strong east to west PBL depth gradient, with higher PBL depths over the semiarid regions of the western US in spring and summer. Many sites located near coastlines exhibited no seasonal cycle due to marine boundary layer influences, and an inverse relationship was found between distance from the coast and observed afternoon PBL depth. Differentiating by climate type, BWk (arid, desert, and cold) has the largest median winter (1075 $\mathrm{m})$ and summer (2500 $\mathrm{m}$ ) PBL depths. Median PBL depths for Cfa (temperate, no dry season, and hot summers), Dfa (cold, no dry season, and warm summer), and Dfb (cold, no dry season, and hot summers) climate types are $750 \mathrm{~m}$ and $1000 \mathrm{~m}$ during winter and summer, respectively.
\end{abstract}

\section{Introduction}

The planetary boundary layer $(\mathrm{PBL})$ is defined as "that part of the troposphere that is directly influenced by the presence of the earth's surface" [1]. The depth of the afternoon PBL is an essential variable in many applications, for example, numerical weather prediction models, inverse carbon transport models, and air quality dispersion models [2], in studies of trace gas variability [3], for characterizing turbulence features in the PBL [4], and for investigating numerous meteorological processes such as convection initiation [5] and aerosol emission and transport processes [6]. Of the various layers of the atmosphere, the PBL is one of the key components of the weather and climate system as it serves as an interface between earth's surface and the free troposphere, affecting energy and mass fluxes [1]. Among many other PBL parameters, the PBL depth, often called the mixing layer depth, is the fundamental parameter that helps to characterize the vertical extent of mixing within the boundary layer and the level at which exchange with the free troposphere occurs. Knowledge of the maximum depth of the PBL is important for studies of air quality and trace gas transport, as it represents the maximum depth to which surface-driven turbulent mixing processes occur [1].

PBL depths can be directly measured using rawinsonde observations [6-8], tethered balloons [9], and masts [10] and using direct measurements from aircraft [11]. PBL depths may also be inferred using a variety of remotely sensed surfacebased platforms, including wind profilers $[12,13]$, aerosol lidars [14], sodars [15, 16], and spaceborne lidars [17-19]. Of these observational platforms available for estimating PBL depths, rawinsonde observations have the longest spatiotemporal coverage around the world. They are available twice daily from hundreds of sites globally, and there are several 
decades' worth of data available at many of these sites. For these reasons, rawinsonde observations are well-suited for climatological studies of PBL depth variability on seasonal to interannual timescales [20-22], despite known limitations in rawinsonde-derived PBL depth estimates $[1,23]$.

Since rawinsonde observations are assimilated into numerical weather prediction models, rawinsondes are released from all sites at the same times each day, most often at 0000 and 1200 UTC. At locations where 1200 UTC occurs in the afternoon local time, rawinsonde launches at these times can provide a reliable estimate of the depth of the quasistationary afternoon PBL, for example, in central and eastern Europe where 1200 UTC coincides with early and middle afternoon hours. However, at other locations, for example, in the eastern US, 0000 UTC corresponds with 1900 LST (UTC $=$ LST + 5). Because 1900 LST is in the early evening local time or very late afternoon hours in summer months, a near-surface stable layer sometimes forms. Recent work has shown that this stable layer can be filtered from the 0000 UTC sounding to estimate the depth of quasistationary afternoon PBL [25] and to compare rawinsonde-derived PBL depths from these locations with other sites in, for example, the western US where 0000 UTC corresponds with 1600 LST $[6,8]$.

In previous work, a groundwork for a global PBL depth climatology was developed [8], where authors evaluated six different approaches for determining PBL depths and provided relevant uncertainty estimates. On the other hand, recent studies [6] on the detailed PBL depth climatology over Europe and the continental US showed enough confidence to investigate further seasonal and interannual variability in PBL depths over different continents. However, when comparing rawinsonde observations with reanalysis products and with climate models, large uncertainties were found for stable conditions. Similarly, other researchers compared seven different methods of estimating PBL depth using GEOS-5 atmospheric general circulation model [9] where only limited comparisons were made using rawinsonde profiles. PBL depth diurnal cycle features in different seasons aggregated by Köppen-Geiger climate classes on a global scale are illustrated in [26]. However, detailed PBL depth seasonal cycle characteristics aggregated to different climate types and geographical locations, in particular over the contiguous US, have so far not been explored. Nevertheless, an investigation of the spatiotemporal, seasonal, and interannual variability of PBL depths for different climatic regions at both continental and global scales is considered important in the regime of today's changing global climate and is initiated in the present study.

To this end, the present study advances previous studies by implementing the technique in [25] to obtain estimates of afternoon PBL depth over all the available routine rawinsonde sites in the contiguous US to facilitate a comparison of the depth of the quasistationary PBL obtained from these sites. This data set is then used to develop a climatology of afternoon PBL depths over the contiguous US. We hypothesized that, even with the implementation of a recently developed technique that filters the near-surface stable layer, afternoon PBL depths will be largest over the intermountain western US because of enhanced aridity over this region. Furthermore, we hypothesized that different climate regimes, aggregated by Köppen-Geiger climate type [26], will show significant differences in seasonal PBL depth variability that are better elucidated with the removal of the sounding's near-surface stable layer. Additionally, we hypothesized that rawinsonde observations from coastal sites will exhibit an inverse relationship between their distance from the coast and the depth of the afternoon PBL. Fulfilling the following objectives is required to evaluate these hypotheses:

(1) Illustrate the potential of a newly developed technique to determine PBL depths from a large rawinsondebased data set consisting of 516,887 soundings collected at 0000 UTC over a 25 -year period at 67 sites located over diverse geographical regions and during a myriad of meteorological conditions in the four different seasons.

(2) Determine the spatial variability in the PBL depth seasonal cycles for seven different geographical regions located over the mainland and along the coastlines.

(3) Investigate the spatial variability in the seasonal cycle patterns aggregated to Köppen-Geiger climate regimes.

To the best of authors' knowledge, this study is the first of its kind to investigate the seasonal variability in afternoon PBL depths over the contiguous US using the Integrated Global Radiosonde Archive (IGRA) radiosonde network. The study provides important insights into the climatological mean seasonal cycles of PBL depth spatial variability for different climate regimes and geographical locations of the contiguous US. Furthermore, the analysis using rawinsonde-derived PBL depths from multiple coastal sites is another novel aspect of this study.

\section{Data and Methods}

2.1. Data Set. As stated in the previous section, we obtained rawinsonde observations from IGRA [27]. Although we acknowledge that other rawinsonde products are available from the Stratospheric Processes and their Role in Climate Data Center (SPARC) [28] and from the University of Wyoming sounding archive [29], IGRA is best suited for multidecadal climatological studies because it has the longest quality-controlled rawinsonde archive.

In the present study, we used daily 0000 UTC rawinsonde launches over a 25 year period from 1 Jan 1991 through 31 Dec 2015. In order for a station to be included in our analyses, at least $60 \%$ of the data set had to be available. For this reason, of the 108 IGRA stations located within the contiguous US (Figure 1), we use data from only 67 of these stations (Table 1). For the stations considered, a data completion of $83 \%$ over the contiguous US during the period of interest was achieved (Figure 2(a)). The stations are located in all dominant climate types in the contiguous US and in all geographic regions. Elevations of the stations range from $5 \mathrm{~m}$ above mean sea level (msl) (Miami, FL) to $2179 \mathrm{~m} \mathrm{msl}$ (Flagstaff, Arizona (AZ) (Figure 2(b)). 


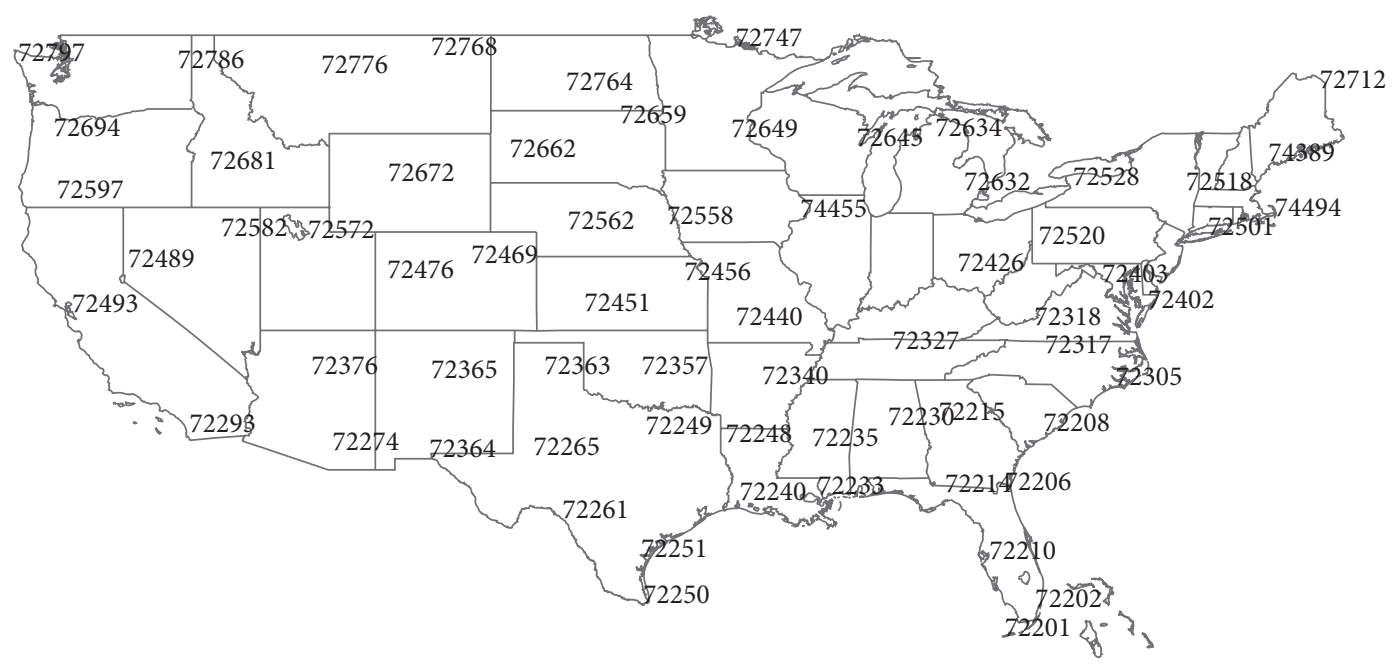

FIGURE 1: 5-digit IGRA station identifications referred to in the present study. See Table 1 for the corresponding station names.

2.2. Determination of Afternoon PBL Depth from the 0000 UTC Sounding. We used the technique presented in [25] to determine the afternoon PBL depth from the 0000 UTC rawinsonde observations. To this end, we first interpolated the rawinsonde data every $100 \mathrm{~m}$ vertically and used these observations to compute the bulk Richardson number $\left(R_{b}\right)$. To determine the PBL depth, we scanned upward in each $R_{b}$ profile, after having removed any near-surface stable layer, and determined the PBL depth as the first height at which $R_{b} \geq R_{c}$. Consistent with [25], we used 0.25 for $R_{c}$.

Analyses of the 0000 UTC rawinsonde observations indicated that the frequency of surface-based inversions increases from west to east across the contiguous US because of the local time when the rawinsonde is launched (Figure 3). The frequency of surface-based inversions ranges from around $5 \%$ along the west coast, where 0000 UTC corresponds with 1600 LST, to $>50 \%$ along the east coast of the US where 0000 UTC occurs at 1900 LST, which is after sunset between approximately September and April.

Because of the frequency of surface-based inversions, particularly over the eastern US, 0000 UTC rawinsonde observations cannot be used to estimate directly the afternoon PBL depth and compare with PBL depths over other regions of the US. Thus, we filtered this surface-based inversion from the 0000 UTC rawinsonde observations. We filtered the surfacebased inversion regardless of the local time of the station (i.e., regardless of whether the station was located on the east coast or on the west coast of the US). We note, though, that more inversions were filtered from soundings on the east coast than on the west coast (cf. Figure 3). To filter the inversion, we followed the technique developed by [25]. Their technique has been shown to produce PBL depths from 0000 UTC rawinsonde observations that agree well with afternoon PBL depths obtained from reanalysis products and with direct measurements from aircraft. For further details on the methodology for deriving PBL depths from the rawinsonde profiles of thermodynamic variables, readers are referred to
[25]. Nevertheless, we note that the application of this method to a large data set is the central focus of the present study.

Also important to note is that the PBL depth computed using the technique developed in [25] is reported relative to ground level, rather than being relative to mean sea level. Calculating PBL height requires adding the station elevation to the PBL depth. However, in the present study, we analyzed PBL depths, rather than PBL heights, in order to remove biases caused by topographical differences among the stations considered.

\section{Results and Discussion}

3.1. General Climatological Characteristics of PBL Depth Seasonal Cycles. Multiyear median PBL depths computed over the period 1991 through 2015 exhibit substantial spatiotemporal variability during all four seasons (Figure 4). Similar spatiotemporal variability is also found in mean PBL depths (not shown). In the present study, though, we include both the monthly means and medians, noting that the latter is less sensitive to outliers. We found that both mean and median PBL depths are lowest in winter (1 Dec through $28 \mathrm{Feb}$ ), with most locations in the US having median PBL depths $<500 \mathrm{~m}$, illustrating little to no variability among these sites during the winter. However, a few sites, located in the southern and central semiarid Rocky Mountains in the southwestern US (i.e., Elko, NV; Riverton, WY; Denver, CO (Colorado); Albuquerque, NM (New Mexico); and Flagstaff, AZ (Arizona)) have median PBL depths around $1200 \mathrm{~m}$ due to orographic influence, prevailing aridity, and dryland ecosystems at those sites [30].

Summertime (1 Jun through 31 Aug) PBL depths are highest over the southwest and intermountain west, where median PBL depths exceed $2000 \mathrm{~m}$, and are lowest at sites along the far west coast and east coast. Figure 4(c) shows that the multiyear median of the summer PBL depths pattern yields 
TABLE 1: Station ID, station name, latitude, longitude, and elevation for stations shown in Figure 1.

\begin{tabular}{|c|c|c|c|c|}
\hline IGRA station ID & Station name & Latitude $\left(^{\circ}\right)$ & Longitude $\left({ }^{\circ}\right)$ & Elevation $(\mathrm{m})$ \\
\hline 72201 & Key West, FL & 24.58 & -81.6 & 6 \\
\hline 72202 & Miami, FL (Florida) & 25.75 & -80.38 & 5 \\
\hline 72206 & Jacksonville, FL & 30.50 & -81.70 & 9 \\
\hline 72208 & Charleston, South Carolina & 32.90 & -80.03 & 15 \\
\hline 72210 & Tampa, FL & 27.70 & -82.38 & 13 \\
\hline 72214 & Tallahassee, FL & 30.45 & -84.30 & 53 \\
\hline 72215 & Atlanta, GA (Georgia) & 33.37 & -84.57 & 244 \\
\hline 72230 & Birmingham, AL (Alabama) & 33.17 & -86.77 & 178 \\
\hline 72233 & Slidell, LA (Louisiana) & 30.33 & -89.82 & 8 \\
\hline 72235 & Jackson, MS (Mississippi) & 32.32 & -90.08 & 91 \\
\hline 72240 & Lake Charles, LA & 30.12 & -93.22 & 10 \\
\hline 72248 & Shreveport, LA & 32.45 & -93.83 & 79 \\
\hline 72249 & Fort Worth, TX (Texas) & 32.80 & -97.30 & 196 \\
\hline 72250 & Brownsville, TX & 25.92 & -97.42 & 7 \\
\hline 72251 & Corpus Christi, TX & 27.78 & -97.51 & 15 \\
\hline 72261 & Del Rio, TX & 29.37 & -100.92 & 314 \\
\hline 72265 & Midland, TX & 31.95 & -102.18 & 873 \\
\hline 72274 & Tucson, AZ (Arizona) & 32.12 & -110.92 & 788 \\
\hline 72293 & San Diego, CA (California) & 32.85 & -117.12 & 132 \\
\hline 72305 & Newport, NC & 34.78 & -76.88 & 11 \\
\hline 72317 & Greensboro, NC (North Carolina) & 36.08 & -79.95 & 275 \\
\hline 72318 & Blacksburg, VA (Virginia) & 37.21 & -80.41 & 640 \\
\hline 72327 & Nashville, TN (Tennessee) & 36.25 & -86.57 & 180 \\
\hline 72340 & Little Rock, AR (Arkansas) & 34.83 & -92.25 & 172 \\
\hline 72357 & Norman, OK (Oklahoma) & 35.23 & -97.47 & 358 \\
\hline 72363 & Amarillo, TX & 35.23 & -101.70 & 1094 \\
\hline 72364 & Santa Teresa, NM (New Mexico) & 31.87 & -106.70 & 1252 \\
\hline 72365 & Albuquerque, $\mathrm{NM}$ & 35.05 & -106.62 & 1619 \\
\hline 72376 & Flagstaff, AZ & 35.23 & -111.82 & 2179 \\
\hline 72402 & Wallops Island, VA & 37.93 & -75.48 & 13 \\
\hline 72403 & Sterling, VA & 38.98 & -77.48 & 86 \\
\hline 72426 & Cincinnati, OH (Ohio) & 39.42 & -83.75 & 323 \\
\hline 72440 & Springfield, MO (Missouri) & 37.23 & -93.38 & 384 \\
\hline 72451 & Dodge City, KS (Kansas) & 37.77 & -99.97 & 791 \\
\hline 72456 & Topeka, KS & 39.07 & -95.62 & 268 \\
\hline 72469 & Denver, CO (Colorado) & 39.76 & -104.87 & 1612 \\
\hline 72476 & Grand Junction, CO & 39.12 & -108.52 & 1475 \\
\hline 72489 & Reno, NV (Nevada) & 39.57 & -119.79 & 1516 \\
\hline 72493 & Oakland, CA & 37.75 & -122.22 & 6 \\
\hline 72501 & Upton, NY (New York) & 40.87 & -72.87 & 20 \\
\hline 72518 & Albany, NY & 42.69 & -73.83 & 93 \\
\hline 72520 & Pittsburgh, PA (Pennsylvania) & 40.53 & -80.23 & 359 \\
\hline 72528 & Buffalo, NY & 42.93 & -78.73 & 218 \\
\hline 72558 & Omaha, NE (Nebraska) & 41.32 & -96.37 & 350 \\
\hline 72562 & North Platte, NE & 41.13 & -100.68 & 847 \\
\hline 72572 & Salt Lake City, UT (Utah) & 40.77 & -111.97 & 1288 \\
\hline 72582 & Elko, NV & 40.86 & -115.74 & 1592 \\
\hline 72597 & Medford, OR (Oregon) & 42.37 & -122.87 & 401 \\
\hline 72632 & White Lake, MI & 42.70 & -83.47 & 329 \\
\hline 72634 & Gaylord, MI (Michigan) & 44.90 & -84.72 & 447 \\
\hline 72645 & Green Bay, WI (Wisconsin) & 44.48 & -88.13 & 214 \\
\hline 72649 & Minneapolis, MN (Minnesota) & 44.85 & -93.57 & 287 \\
\hline
\end{tabular}


TABLE 1: Continued.

\begin{tabular}{|c|c|c|c|c|}
\hline IGRA station ID & Station name & Latitude $\left({ }^{\circ}\right)$ & Longitude $\left({ }^{\circ}\right)$ & Elevation $(\mathrm{m})$ \\
\hline 72659 & Aberdeen, SD (South Dakota) & 45.45 & -98.41 & 397 \\
\hline 72662 & Rapid City, SD (South Dakota) & 44.07 & -103.21 & 1027 \\
\hline 72672 & Riverton, WY & 43.07 & -108.49 & 1703 \\
\hline 72681 & Boise, ID (Idaho) & 43.57 & -116.22 & 871 \\
\hline 72694 & Salem, OR & 44.92 & -123.02 & 61 \\
\hline 72712 & Caribou, ME (Maine) & 46.87 & -68.02 & 191 \\
\hline 72747 & International Falls, $\mathrm{MN}$ & 48.57 & -93.38 & 359 \\
\hline 72764 & Bismarck, ND (North Dakota) & 46.77 & -100.75 & 505 \\
\hline 72768 & Glasgow, MT (Montana) & 48.21 & -106.63 & 694 \\
\hline 72776 & Great Falls, MT & 47.46 & -111.38 & 1130 \\
\hline 72786 & Spokane, WA (Washington) & 47.68 & -117.63 & 728 \\
\hline 72797 & Quillayute, WA & 47.95 & -124.55 & 56 \\
\hline 74389 & Gray, ME & 43.90 & -70.25 & 125 \\
\hline 74455 & Davenport, IA (Iowa) & 41.62 & -90.58 & 229 \\
\hline 74494 & Chatham, MA & 41.67 & -69.97 & 16 \\
\hline
\end{tabular}

a strong east to west PBL depth gradient, with higher PBL depths over the western states. These findings are consistent with the spatial distribution of the PBL depths inferred from, for example, spaceborne lidar measurements [17]. The presence of a strong east to west gradient is also consistent with previous rawinsonde climatologies [6], in which the near-surface stable layer was not filtered from the 0000 UTC sounding. The limitation due to differences in local sampling times in the US and Europe was also mentioned by [6].

However, we note that PBL depths during the summer and autumn over the central and eastern US in the present study are about 200-400 $\mathrm{m}$ larger than those reported in previous rawinsonde climatologies [6]. The larger PBL depths in the present study are more realistic estimates of afternoon PBL depths over these regions. The depths better agree with daytime PBL depths obtained from, for example, aircraft observations and reanalysis products [25], thereby underscoring the importance of filtering the near-surface stable layer from the 0000 UTC sounding to obtain afternoon PBL depth estimates over the contiguous US. Additionally, we have classified the PBL regimes with respect to different climate types in the US (Section 3.3).

Spatial variability in the PBL depths during the transitional seasons (i.e., spring and autumn) also yields a similar pattern for the east to west PBL depth gradient, although the pattern is not as strong as that during the summer. In particular, during spring, moderately high $\mathrm{PBL}$ depths (median values of around $1900 \mathrm{~m}$ ) are observed over the sites in the western US and over the Rocky Mountains. For example, two sites in New Mexico (Albuquerque and Santa Teresa) and one site in western Colorado (Grand Junction) (cf. Table 1 and Figure 1) do not exhibit any difference between PBL depth in spring and summer. At these sites, median PBL depths are around $2000 \mathrm{~m}$ in both seasons. In contrast with these sites in the western US, sites in the eastern US have much smaller differences in PBL depth between winter and summer. Additionally, there are considerable differences in PBL depth spatial variability over the western US during the spring and autumn that are most likely caused by heterogeneous land surface characteristics.

3.2. PBL Depth Seasonal Cycles over Different US Regions. One of the advantages of routine rawinsonde observations over the US is its widespread coverage over almost all sectors and states. To help elicit spatial patterns in PBL depth variability, we classified the IGRA sounding stations into the seven geographic regions: Northeast, Southeast, Midwest, Northern Great Plains, Southern Great Plains, Pacific Northwest, and Southwest (Figure 5). We grouped the stations into these regions so that there was approximately the same number of stations within each region (Table 2) and our statistics were not skewed. Another notion behind the classification is that, within many scientific studies of different US regions, PBL depth seasonal variability and the knowledge about its spatial pattern become often essential. We believe that a detailed PBL depth seasonal cycle climatology over different US regions is beneficial for the research community to design future studies and short-term field experiments for air quality, cloud development, and the carbon cycle research.

In addition to the seven regions that we identified, we included an eighth classification into which we grouped the 20 coastal stations. We defined a coastal station as being within $60 \mathrm{~km}$ of the Pacific Ocean, Atlantic Ocean, Gulf of Mexico, or the Great Lakes, as the local-scale influences of the body of water can extend well inland away from the coast. Additionally, we tested various distances from the shoreline to the rawinsonde sites, as shown in Figure 6. For example, when using a distance of, for example, $30 \mathrm{~km}$, there were an insufficient number of samples (11) to obtain meaningful results. Nevertheless, we note that studying the relationship between the distance from the shoreline and corresponding changes in the PBL depth is the key aim here, although we 


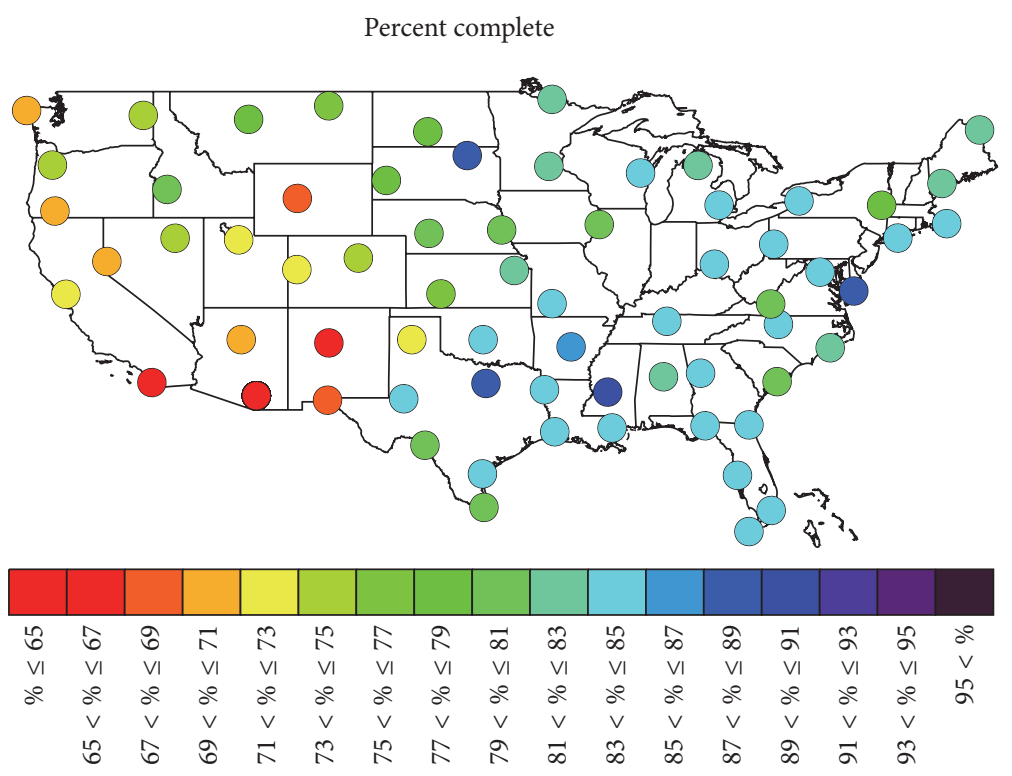

(a)

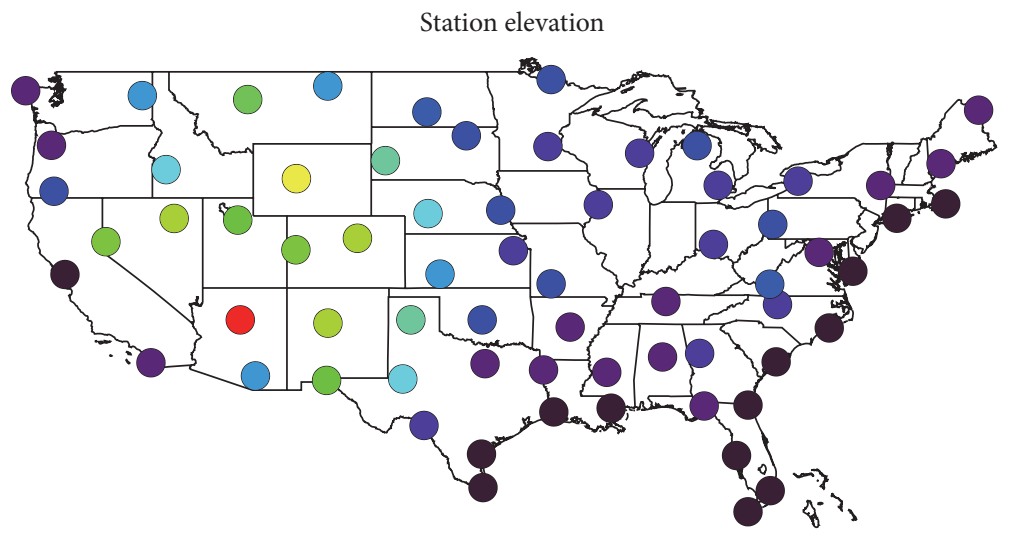

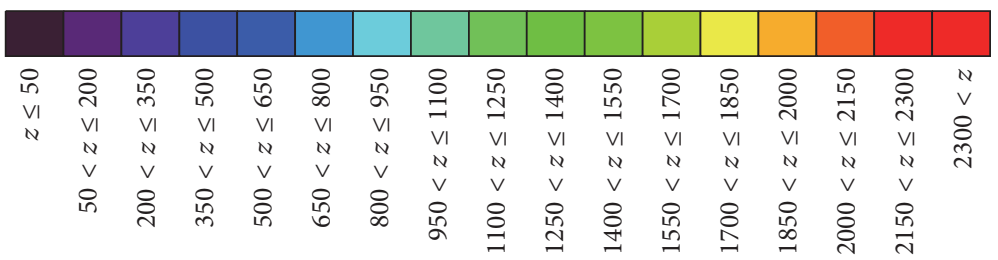

(b)

FIGURE 2: Data completion, 1 Jan 1991 through 31 Dec 2015, in the IGRA 0000 UTC sounding with a threshold of at least 65\% of data availability at those sites (a); see color bar scale limit on the right varying between $<65 \%$ and $>95 \%$ of data availability. Panel (b) shows station elevation $(z)$ in $\mathrm{m}$ msl illustrating diverse characteristics of the sites, with surface elevation varying between near sea level and $>2100 \mathrm{~m} m s l$.

acknowledge that the choice of $60 \mathrm{~km}$ from the coastal line is somewhat subjective.

Of the seven regions over the mainland US that we identified, although all the regions yield well-defined seasonal cycle with higher PBL depths in summer and lower in winter, we noted that the smallest month-to-month variability in PBL depths occurred in the Northeast. In the Northeast, PBL depths range from $750 \mathrm{~m}$ during the winter to around $1000 \mathrm{~m}$ in late spring and early summer, which illustrate a small seasonal cycle amplitude of PBL depths (Figure 7). Additionally, PBL depths at sites in the Southeast do not show any substantial variability on monthly or seasonal timescales (Figure 7(f)). The absence of variability at these timescales is evident by the large scatter among these sites, which indicates similar land surface characteristics governing the seasonal scale PBL depth variability.

Moving west from these regions, we noted an increase in the PBL depth variability, with larger PBL depths during the summer over the Midwest (Figure 7(c)) and Northern Great Plains (Figure 7(b)) than over the Northeast (Figure 7(f)). Over the Southwest US (Figure 7(e)), PBL depths show the largest range over the year as compared with the other 


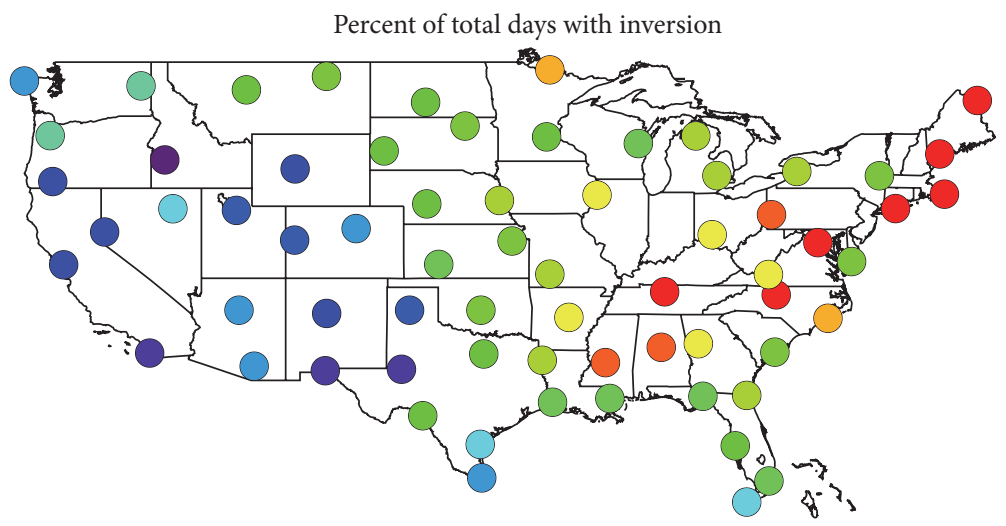

\begin{tabular}{|c|c|c|c|c|c|c|c|c|c|c|c|c|c|c|c|c|}
\hline in & $\infty$ & 二 & $\underset{J}{ \pm}$ & 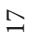 & 요 & $\widetilde{\sim}$ & $\underset{\sim}{\sim}$ & จे & $\approx$ & $\stackrel{n}{m}$ & $\stackrel{\infty}{m}$ & $F$ & $\not$ & F & in & $\alpha^{\circ}$ \\
\hline $\begin{array}{ll}\mathrm{VI} \\
0\end{array}$ & $\mathrm{VI}$ & VI & $\mathrm{VI}$ & $\mathrm{Vl}$ & VI & VI & $\mathrm{VI}$ & $\mathrm{Vl}$ & $\mathrm{Vl}$ & VI & $\mathrm{VI}$ & VI & $\mathrm{Vl}$ & $\mathrm{Vl}$ & $\mathrm{VI}$ & 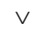 \\
\hline 20 & de & $\partial^{\circ}$ & $\partial^{\circ}$ & $\partial^{\circ}$ & $\partial^{\circ}$ & $\partial^{e}$ & $\partial^{\circ}$ & $\partial^{e}$ & $\partial^{e}$ & $\partial^{e}$ & $\partial^{\circ}$ & $\partial^{e}$ & $a^{e}$ & $\partial^{e}$ & $\partial^{e}$ & 으 \\
\hline & in & $\vee$ & $\vee$ & V & $\vee$ & $\vee$ & $\vee$ & V & $\vee$ & $\vee$ & $\vee$ & $\vee$ & 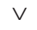 & $\vee$ & $\vee$ & \\
\hline & & $\infty$ & $\exists$ & 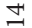 & 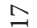 & 오 & $\ddot{\sim}$ & $\stackrel{0}{0}$ & ฮิ & กै & $\stackrel{10}{n}$ & $\stackrel{\infty}{m}$ & $\exists$ & $\stackrel{H}{F}$ & 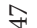 & \\
\hline
\end{tabular}

(a)

00 UTC local time
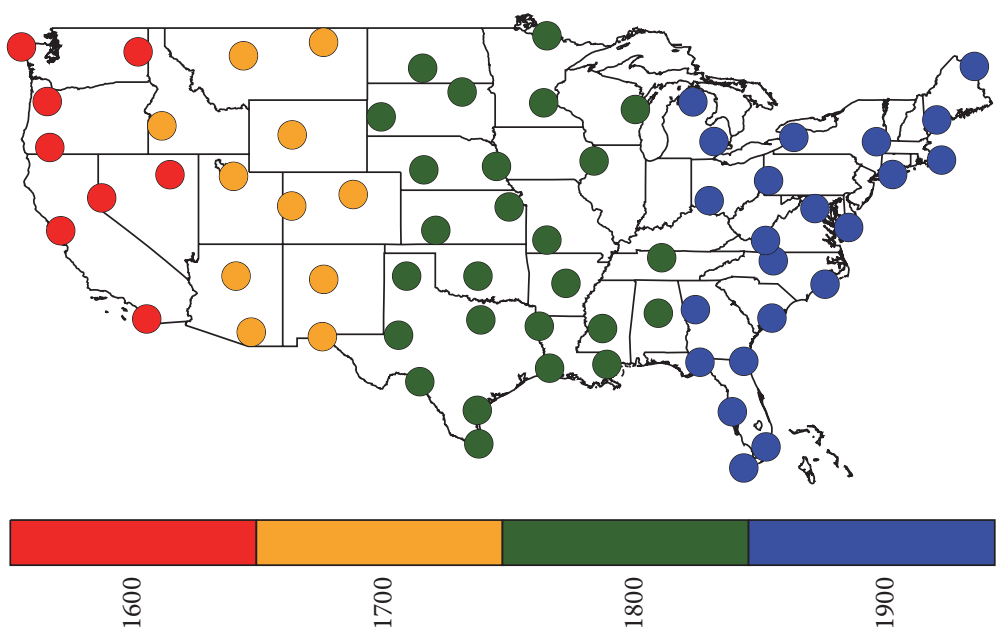

(b)

FIgURE 3: Percent of times, 1 Jan 1991 through 31 Dec 2015, when there is a near-surface $(<100 \mathrm{~m})$ inversion present in the IGRA 0000 UTC sounding (a). Panel (b) shows the local time of 0000 UTC sounding illustrating the four different time zones in the study region.

regions. For example, in January, the median PBL depth across all stations in the Southwest is $1000 \mathrm{~m}$ but is around $2400 \mathrm{~m}$ in June.

Flagstaff, AZ, is the notable exception. During the winter, PBL depths at Flagstaff are larger than other stations in the Southwest, and PBL depths are lower than all other stations during the other seasons, particularly during summer (cf. Figure 4). The lower PBL depths during the summer occur because Flagstaff is more susceptible to the influences of the monsoon in July and August than other sites in the Southwest [31]. The site has the highest elevation of the 67 sites in the present study and is located along the southern edge of the Colorado Plateau. Increased moisture transport into the Southwest results in Flagstaff receiving about twice as much rainfall as surrounding sites. With higher rainfall amounts in July and August, there is more water available for latent heat flux at Flagstaff than at other nearby sites. Higher latent fluxes reduce the amount of net radiation available for sensible heat flux, reducing median PBL depths during the summertime. The larger PBL depths observed at Flagstaff during the winter than at other sites in the Southwest are also due to localscale influences on PBL depth. Many sites in the Southwest are located in valleys and thus are more susceptible to lowlevel inversions [32] during the wintertime, resulting in lower PBL depths at these locations than at sites like Flagstaff located on mountains or plateaus. Additionally, Flagstaff's location on a plateau makes it more susceptible than other sites in the region to dynamically driven and thermally driven flows, which modify PBL evolution and the depth of the quasistationary afternoon PBL. However, a detailed investigation of these flows on the PBL depths at Flagstaff is beyond the scope of the present study. 


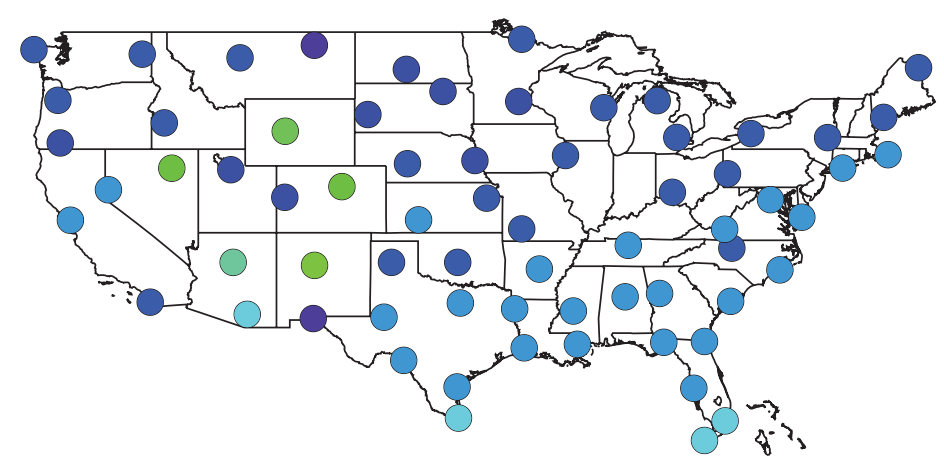

(a)

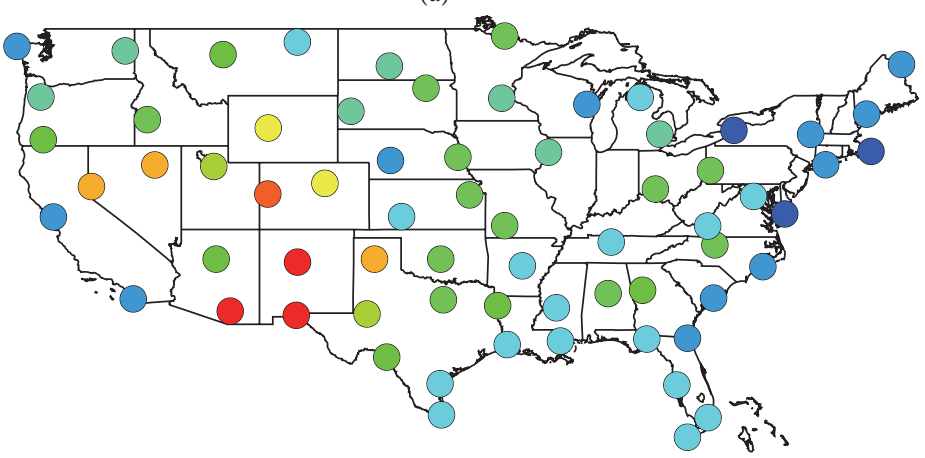

(b)

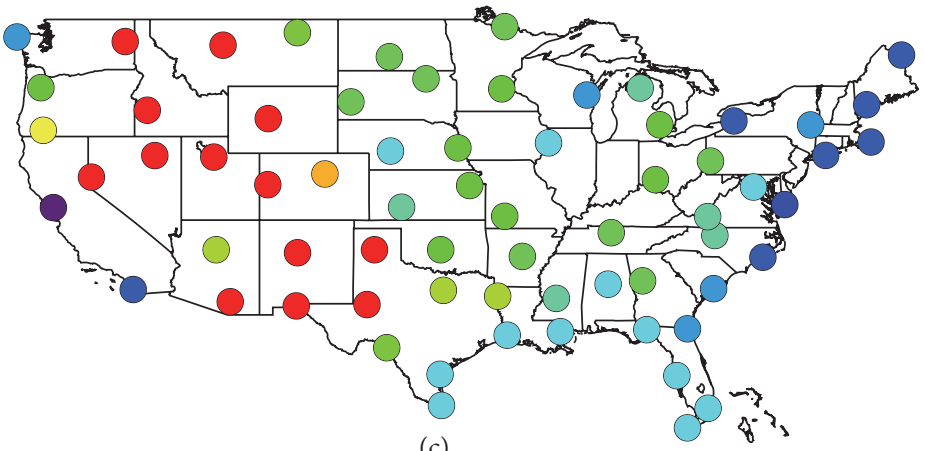

(c)

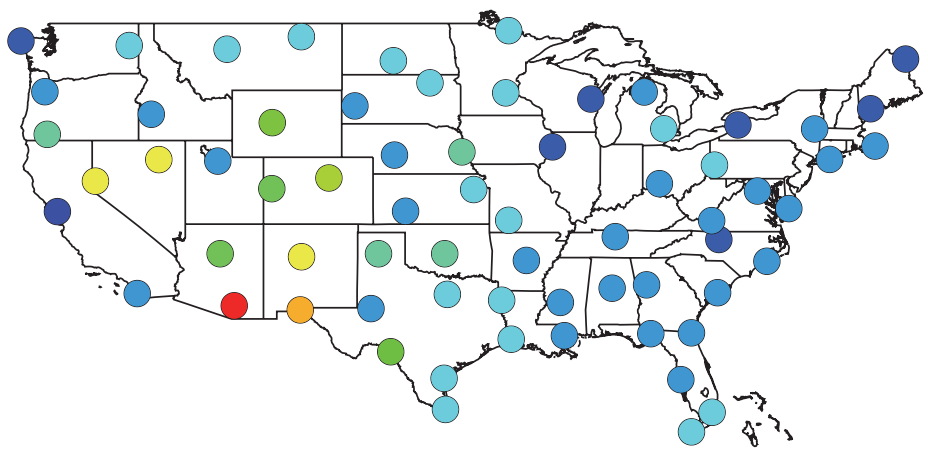

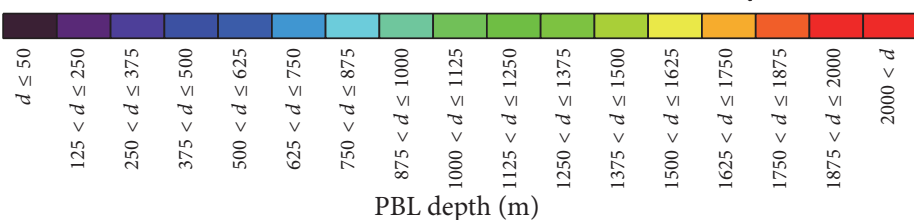

(d)

Figure 4: Median PBL depths (d), from 1 Jan 1991 through 31 Dec 2015, in winter (panel (a)), spring (panel (b)), summer (panel c), and autumn (panel (d)) emphasizing the climatological median PBL depth seasonal cycle at the IGRA sites and the relevant spatial variability over the contiguous US in the four different seasons. A broad color bar scale limit (m) for PBL depths was chosen to cover the seasonal variability revealed in the measurements. 
TABLE 2: Geographic regions of the contiguous US, number of IGRA stations, and latitude and longitude bounds.

\begin{tabular}{|c|c|c|}
\hline Region & Number of IGRA stations & Latitude and longitude \\
\hline \multirow{2}{*}{ Northwest } & \multirow{2}{*}{7} & Latitude: north of $42.0^{\circ} \mathrm{N}$ \\
\hline & & Longitude: west of $103.0^{\circ} \mathrm{W}$ \\
\hline \multirow{2}{*}{ Northern Great Plains } & \multirow{2}{*}{7} & Latitude: north of $37.0^{\circ} \mathrm{N}$ \\
\hline & & Longitude: west of $94.0^{\circ} \mathrm{W}$ and east of $103.0^{\circ} \mathrm{W}$ \\
\hline \multirow{2}{*}{ Upper Midwest } & \multirow{2}{*}{5} & Latitude: north of $37.5^{\circ} \mathrm{N}$ \\
\hline & & Longitude: west of $82.5^{\circ} \mathrm{W}$ and east of $94.0^{\circ} \mathrm{W}$ \\
\hline \multirow{2}{*}{ Southern Great Plains } & \multirow{2}{*}{5} & Latitude: south of $37.0^{\circ} \mathrm{N}$ \\
\hline & & Longitude: west of $94.0^{\circ} \mathrm{W}$ and east of $103.0^{\circ} \mathrm{W}$ \\
\hline \multirow{2}{*}{ Southwest } & \multirow{2}{*}{9} & Latitude: south of $42.0^{\circ} \mathrm{N}$ \\
\hline & & Longitude: west of $103.0^{\circ} \mathrm{W}$ \\
\hline \multirow{2}{*}{ Northeast } & \multirow{2}{*}{6} & Latitude: north of $37.0^{\circ} \mathrm{N}$ \\
\hline & & Longitude: east of $82.5^{\circ} \mathrm{W}$ \\
\hline \multirow{2}{*}{ Southeast } & \multirow{2}{*}{8} & Latitude: south of $37.0^{\circ} \mathrm{N}$ \\
\hline & & Longitude: east of $94.0^{\circ} \mathrm{W}$ \\
\hline
\end{tabular}

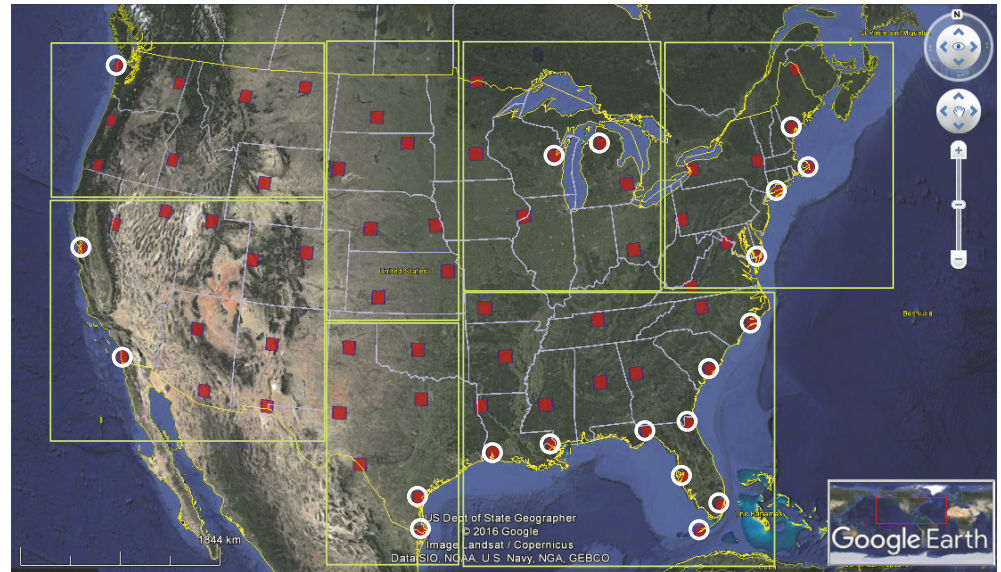

FIGURE 5: Location of IGRA sites overlaid on Google Earth image with seven regions marked by yellow boxes. US state boundaries are marked with gray line. The coastal sites (20) are marked with white circles around the red squares. Source of the satellite image () Google Earth Inc.

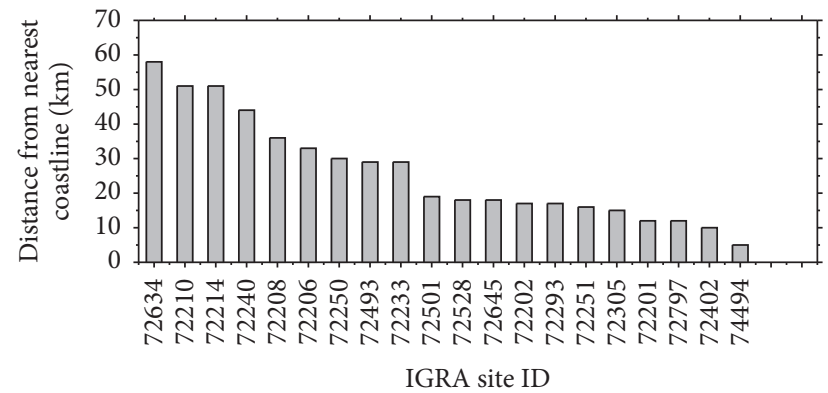

FIGURE 6: Distance (in $\mathrm{km}$ ) of the 20 IGRA rawinsonde sites (with complete data sets) from the nearest coastline.

As with the Southwest, PBL depths over the Northwest also exhibit a well-defined seasonal cycle (cf. Figure 7(a)). The largest PBL mean and median PBL depths are observed in July, with median PBL depths of around $1700 \mathrm{~m}$ agl. The smallest median PBL depths are $650 \mathrm{~m}$ agl and occur in
January. There also existed considerable variability in PBL depths within a given month among sites in the Northwest due to the variety of land surface characteristics and climate types for the sites located within this region.

Among the seven regions considered here, we found that the median and mean seasonal cycles over the Northeast and Southeast reveal similar patterns and nearly identical summer to winter contrasts, with differences around $500 \mathrm{~m}$ in the median PBL depths. The contrast in PBL depths over the Northern Great Plains (cf. Figure 7(b)), where winter to summer temperature contrasts are larger, surprisingly is only slightly larger than over the Northeast and Southeast, although we do note larger within-month variability in July and August. Four of the sites in the Northern Great Plains region are located on the downwind side of the Rocky Mountains. Previous studies $[30,33]$ illustrated that the PBL depth on the downwind side of the mountain is often influenced by $\mathrm{PBL}$ regimes over the mountains. As a result, elevated PBL depths are frequently observed on the downwind side of the mountains. Thus, winter PBL depths over some of the sites 


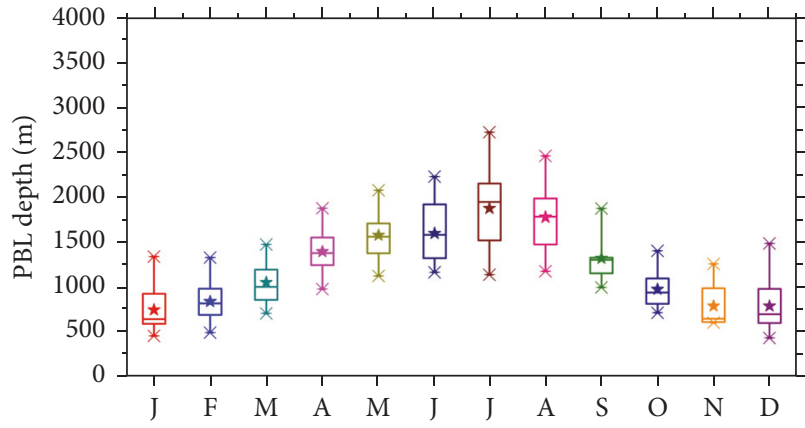

(a) Northwest $(N=7)$

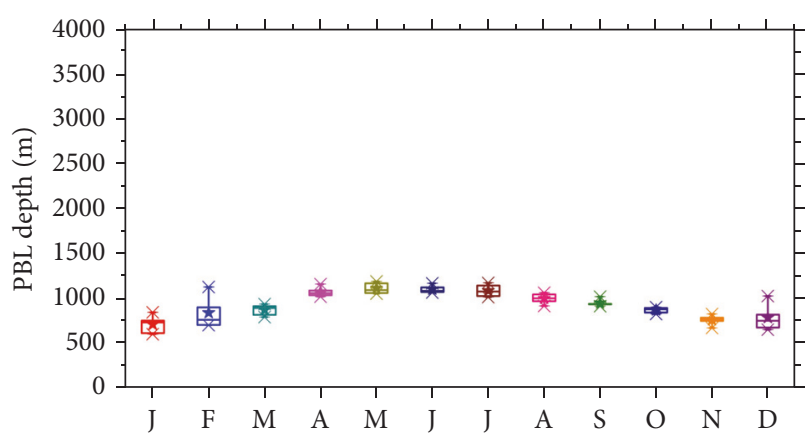

(c) Upper Midwest $(N=5)$

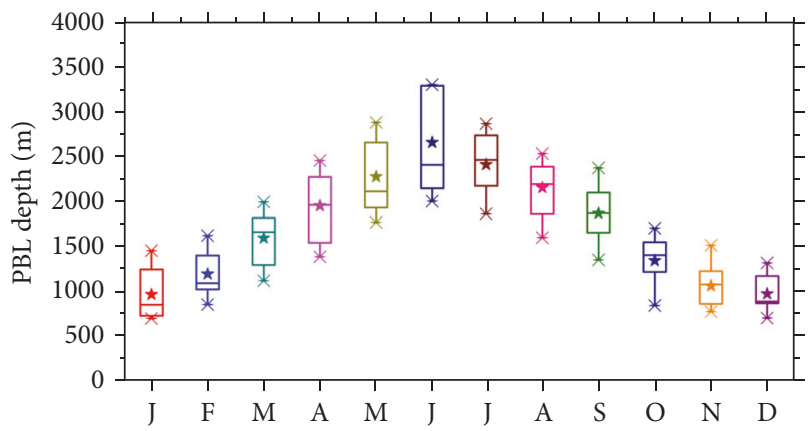

(e) Southwest $(N=9)$

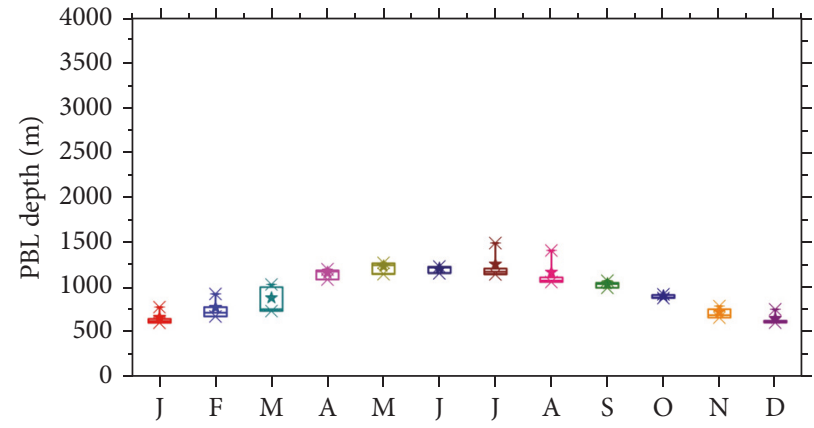

(b) Northern Great Plains $(N=7)$

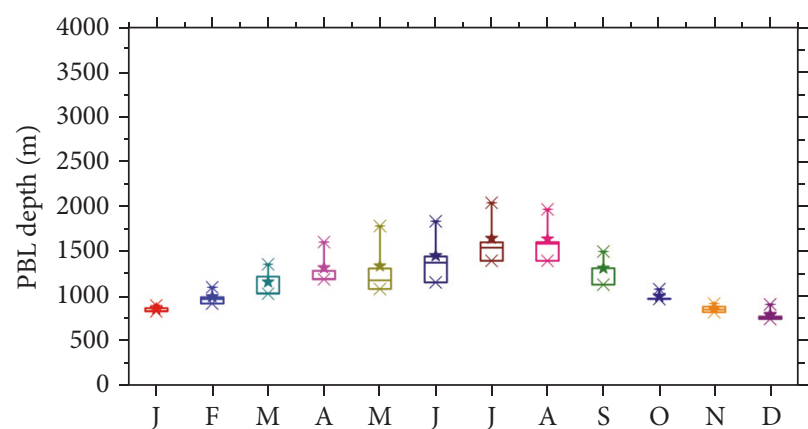

(d) Southern Great Plains $(N=5)$

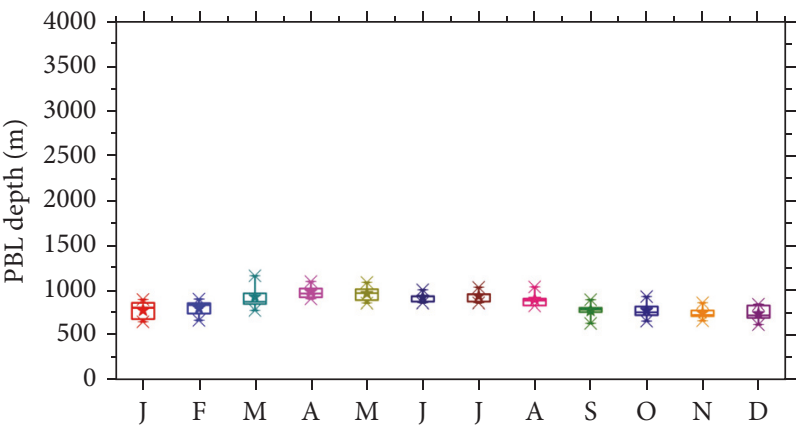

(f) Northeast $(N=6)$

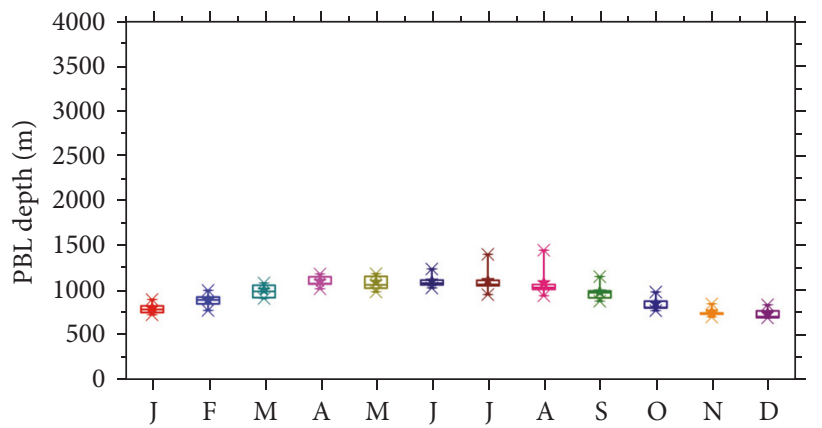

(g) Southeast $(N=8)$

FIgURE 7: Spatial variability of PBL depth over different sectors of the contiguous US, illustrating low seasonal scale amplitudes of PBL depths $(<300 \mathrm{~m})$ over Northern Great Plains (b), Upper Midwest (c), Northeast (f), and Southeast (g) regions, relatively higher amplitudes (>1000 m) over Northwest (a) and Southwest (e) regions, and moderate seasonal scale amplitude over Southern Great Plains (d). Seasonal scale amplitudes were determined by subtracting median winter PBL depths from summer median PBL depths. Stars indicate mean; horizontal line represents median; boxes indicate the 25 th and 75 th percentiles; X's indicate 10th and 90th percentiles. 

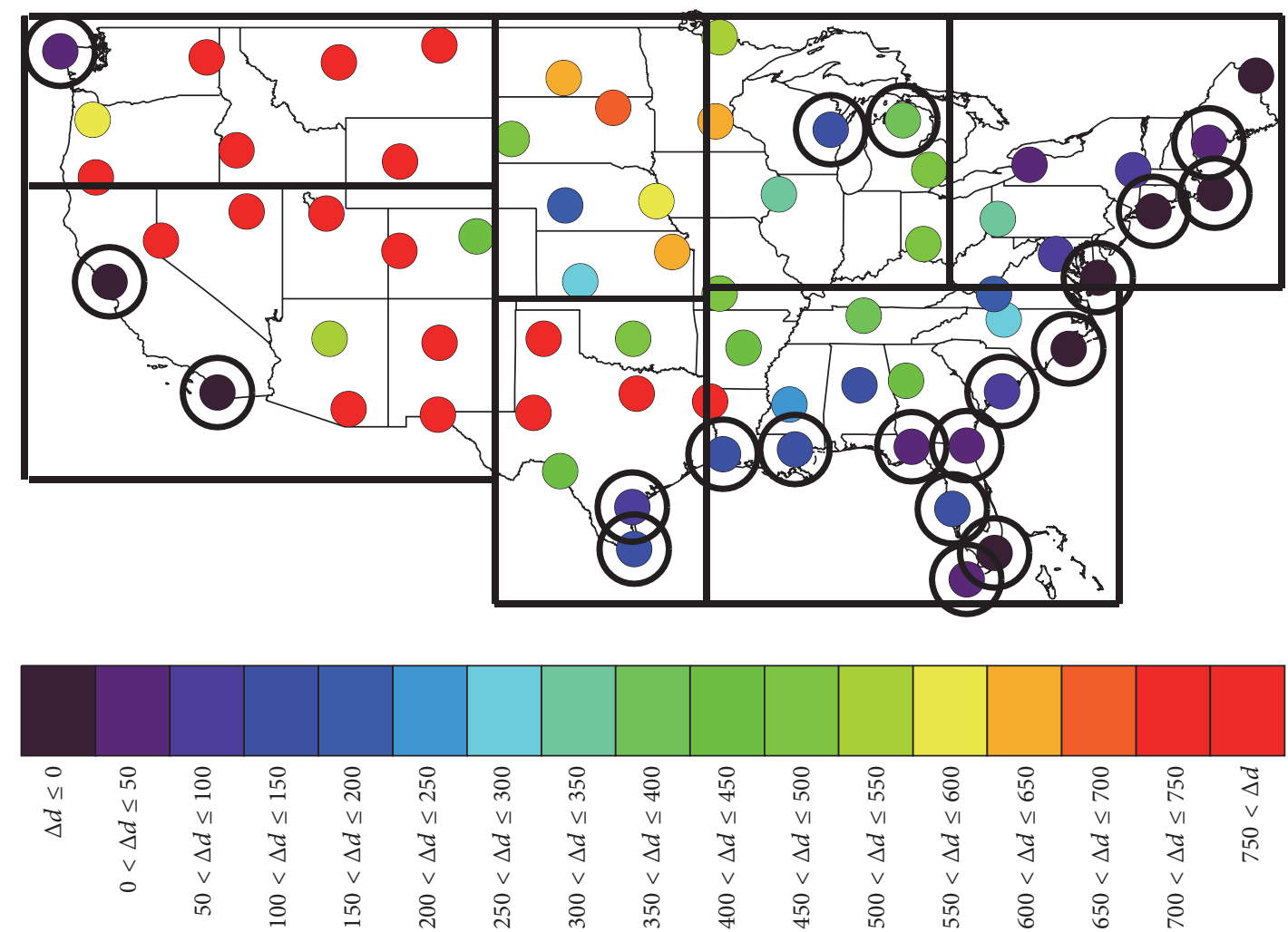

FIGURE 8: Seasonal contrasts in PBL depths (in $\mathrm{m}$ ) obtained by subtracting median winter PBL depths from summer median PBL depths $(\Delta d)$ elucidate a diverse nature of PBL depth seasonal cycles among seven sectors of the study region. Black boxes mark the seven different US sectors shown in Table 2. Sites located in close proximity to coastlines and lakes are marked with black circles around the colored symbols. These sites showed very small ( $\sim 100 \mathrm{~m}$ or less) seasonal contrasts (see Section 3.4 for further details).

are elevated, which most likely influences the summer to winter PBL depth differences. Nevertheless, PBL depth is not solely governed by the sensible heat flux. Other factors such as subsidence, flow regimes, free atmospheric dynamics, and cloud cover (in particular PBL clouds) also control the PBL depth variability on both seasonal and diurnal time scales [34].

Additionally, PBL depths over the Northwest, Southwest, and Southern Great Plains are characterized by similar seasonal cycle patterns and larger summer to winter contrasts between $800 \mathrm{~m}$ and $2000 \mathrm{~m}$. These results provided us with confidence in analyzing and quantifying in detail the seasonal contrasts in retrieved PBL depths via subtracting winter depths from summer depths over all the IGRA sites and are addressed in the next section.

\subsection{Seasonal PBL Depth Change and Relevant Spatial Pattern.} To elicit the seasonal change in PBL depths and spatial pattern independent of a station's proximity to water, we subtracted the winter median PBL depths from the summer median PBL depths as illustrated in Figure 8. At most locations, summer PBL depths are at least 500-1000 m larger than winter PBL depths, but there are notable exceptions, particularly at coastal stations where summer PBL depths are smaller than winter PBL depths, as indicated by the dark purple circles in Figure 8. In general, the PBL depth seasonal contrast is larger in the western US (i.e., 300-800 m) than in the eastern US (i.e., 50-300 m). Also, the seasonal PBL depth contrast over the sites located within three US sectors, namely, the Northwest, Southwest, and Southern Great Plains, is large. In particular, the contrast is largest $(>700 \mathrm{~m}$, which corresponds with the warm colors in Figure 8) for most of the sites located along the western side of the Rocky Mountains. Most of the sites in the eastern US have a median PBL depth difference $<$ $300 \mathrm{~m}$.

The spatial variability in the seasonal PBL depth change over the Northern Great Plains region is very high, as the differences between median PBL depths between summer and winter vary from $100 \mathrm{~m}$ to $700 \mathrm{~m}$ over this region (cf. Figure 8). The large variability in PBL depth differences over this region can be attributed to the diverse land surface, mixed orography, and mixed land cover/land use over this region compared with the other regions $[6,35]$.

When considering variability in the seasonal PBL depth changes, the largest contrast is observed at Santa Teresa, NM, and Grand Junction, $\mathrm{CO}$ (cf. Figure 1 and Table 1), where the median differences are $2259 \mathrm{~m}$ and $2074 \mathrm{~m}$, respectively. In contrast, there is little or no variation over the sites located along the coastline and near the Great Lakes. Stations at which median PBL depths are lower during the summer than during the winter are along the coast. Of the seven stations with smaller PBL depths in the summer than winter (i.e., 
$\Delta d<0$ ), Oakland, CA, has the largest median difference (i.e., PBL depths are $537 \mathrm{~m}$ lower in the summer than during the winter). In summary, deeper estimates of PBL depth are found over land than over the sites located near or at close proximity to the coastlines, and the seasonal PBL depth contrast is sensitive enough to identify the sites located along the coastlines. Thus, the PBL depth seasonal cycle features over the coastal sites are explicitly discussed in the next section.

3.4. PBL Depth Seasonal Cycles at Coastal Sites. Using IGRA database of rawinsonde profiles, we selected 20 coastal sites using the criterion that their location is within $60 \mathrm{~km}$ from the nearest coastline. However, we noted that the coastal sites selected here are characterized by different types of land surface and geography. These sites are also located at a range of different distances from the nearest coastlines (cf. Figure 6). Clearly observed is that few sites are located more than $50 \mathrm{~km}$ from the coastline; some are around $30 \mathrm{~km}$, but a majority of the sites are located within $20 \mathrm{~km}$ distance of the coastlines. Based on the previous studies, we hypothesized that the influence of marine boundary layer features on the PBL depth variability over those sites is inversely related to the distance between the rawinsonde sites and the nearest coastlines. Also, in the previous section we noted that the PBL depth seasonal contrast over most of the coastal sites $(<100 \mathrm{~m})$ is much smaller than that over land, indicating a weaker seasonal cycle in PBL depths at the coastal sites.

For brevity, we present the climatological median seasonal cycles of PBL depths for all the sites using the Hovmöller-type diagram in Figure 9 in which the $x$-axis indicates the different months, the $y$-axis denotes the different coastal sites, and the colors indicate PBL depths. Additionally, we arranged the sites along the $y$-axis according to the site's distance from the coastline. Whereas a distinct seasonal cycle in PBL depths is present among the seven different regions discussed in Section 3.2, there is no obvious seasonal pattern in PBL depth variability for the 20 coastal sites identified (Figure 9).

Furthermore, there is no consistent pattern for stations located along the same body of water. Instead, the monthly cycle in median PBL depths is largely driven by a station's proximity to the coast. The stations that are located within $15 \mathrm{~km}$ of the coast (i.e., Key West, FL; Quillayute, WA; Wallops Island, VA; and Chatham, MA) (cf. Figure 1 and Table 1) have the smallest variability in PBL depth during the year. Sites that are located farther inland and away from the coast (e.g., Lake Charles, LA, and Tallahassee, FL) have maximum PBL depths in the spring that is more characteristic of other stations located in the same region that are farther inland. Therefore, these results confirm that the seasonal difference amplitudes (i.e., median winter PBL depth subtracted from the median summer PBL depth) over the sites located farther inland are substantially larger than those over the sites located in close proximity to the ocean or to the Great Lakes. Based on a 10-year climatology of PBL depth using general circulation models and relevant PBL mass budgets, [34] also found substantial land-sea contrasts in PBL depth, which is consistent with our findings.
However, Oakland, CA, is the exception, as PBL depths over this site are significantly lower during the summer than during the winter and spring. This finding is consistent with previous studies of PBL depth over central California, where shallower PBL depths during the summer than during the winter and spring are attributed to the mid to late afternoon horizontal advection of stable marine boundary layer air that penetrates well inland away from the coast [12]. Additionally, [36] used long-term measurements of radiosonde-derived PBL depths over Hong Kong and found similar features of the PBL depth seasonal cycles (i.e., lower PBL depths in summer than in the winter). Such PBL depth seasonal cycle features at coastal sites in the midlatitudes were also reported in [36]. Using the GPS radio occultation data sets of vertical profile of refractivity from the COSMIC satellite mission, [36] derived zonally averaged monthly mean PBL depth departures from annual mean PBL depths over the sea and land to confirm their findings on the homogenous seasonal cycle of the marine boundary layer.

Furthermore, the absence of a clear seasonal cycle among the coastal sites is well-known from previous studies [6, 26] and is attributed to the moderating influences of the water. However, the analysis presented here for rawinsondesderived PBL depths for multiple coastal sites is the first of its kind. At 7 of the 20 sites, PBL depths decrease between January and June, with the largest differences, on the order of 300-400 m, occurring at sites along the US west coast. In future studies, we will apply our hypotheses and use similar criteria based on the distance between the rawinsonde sites and nearest coastlines to investigate further the temporal differences and latitudinal gradients (if any) in coastal versus inland PBL depths at the $>200$ global coastal sites during multiple years.

3.5. PBL Depth Spatial Variability by Climate Regime. In previous sections, we documented the seasonal variability of PBL depth over different regions of the US. To relate these patterns to local climate, we grouped the continental stations (i.e., those stations that are not located near the coastlines of oceans or of the Great Lakes) by climate type using the Köppen-Geiger climate classification [24, 37] (Table 3 and Figure 10).

Ten climate types were identified across the continental stations: Cfa, Dfb, BSk, Dfa, Dsb, Bsh, BWk, Dsa, Csa, and Csb (see $[24,37]$ for a full description of these climate types). Climate type $\mathrm{Cfa}$, characterized by temperate climate, no dry season, and hot summers, is most common among the stations used in the present study and accounts for $25 \%$ of all stations (Figure 10). Climate types Dfb (cold, without dry season, and hot summer), BSk (arid, steppe, and cold), and Dfa (cold, without dry season and warm summer) are the next most common climate types among the IGRA stations considered.

Stations in the Cfa climate type show remarkable similarity among the different months (Figure 11). During the winter months, PBL depth variability among the different sites is insignificant, and the PBL depth change from spring to summer is negligible. Instead, the largest deviations among the sites occur between June and September, with Fort Worth, 
TABLE 3: Description of Köppen climate classifications identified in the present study with the list of IGRA sites located within these regions.

\begin{tabular}{lccc}
\hline Climate type & Characteristics & \# of sites & Site ID: locations \\
\hline Cfa & Temperate; without dry season; hot summer & 12 & $\begin{array}{c}\text { 72215: Atlanta, GA; 72230: Birmingham, AL; 72235: Jackson, MS; } \\
\text { 72248: Shreveport, LA; 72249: Fort Worth, TX; 72317: Greensboro, } \\
\text { NC; 72318: Blacksburg, VA; 72327: Nashville, TN; 72340: Little Rock, } \\
\text { AR; 72357: Norman, OK; 72403: Sterling, VA; 72440: Springfield, IL }\end{array}$ \\
\hline Dfb & Cold; without dry season; hot summer & 8 & $\begin{array}{c}\text { 72528: Buffalo, NY; 72632: White Lake, MI; 72649: Minneapolis, MN; } \\
\text { 72659: Aberdeen, SD; 72672: Riverton, WY; 72747: International Falls, } \\
\text { MN; 72764: Bismarck, ND; 72712: Caribou, ME }\end{array}$ \\
\hline BSk & Arid; steppe; cold & & $\begin{array}{c}\text { 72451: Dodge City, KS; 72469: Denver, CO; 72476: Grand Junction, } \\
\text { CO; 72363: Amarillo, TX; 72265: Midland, TX; 72662: Rapid City, SD; } \\
\text { 72681: Boise, ID; 72768: Glasgow, MT; 72776: Great Falls, MT. }\end{array}$ \\
\hline Dfa & Cold; without dry season; warm summer & 7 & $\begin{array}{c}\text { 72518: Albany, NY; 72520: Pittsburgh, PA; 72456: Toepka, KS; 72426: } \\
\text { Cincinnati, OH; 72558: Omaha, NE; 72562: North Platte, NE; 74455: } \\
\text { Davenport, IA }\end{array}$ \\
\hline Dsb & Cold; dry, warm summer & 3 & 72376: Flagstaff, AZ; 72489: Reno, NV; 72786: Spokane, WA \\
\hline BWk & Arid; desert; cold & 2 & 72364: Santa Teresa, NM; 72365: Albuquerque, NM \\
\hline BSh & Arid; steppe; hot & 2 & 72261: Del Rio, TX; 72274: Tuscon, AZ \\
\hline Dsa & Cold; dry, hot summer & 2 & 72572: Salt Lake City, UT; 72582: Elko, NV \\
\hline Csa & Temperate; dry, hot summer & 1 & 72597: Medford, OR \\
\hline Csb & Temperature; dry, cool summer & 1 & 72694: Salem, OR
\end{tabular}

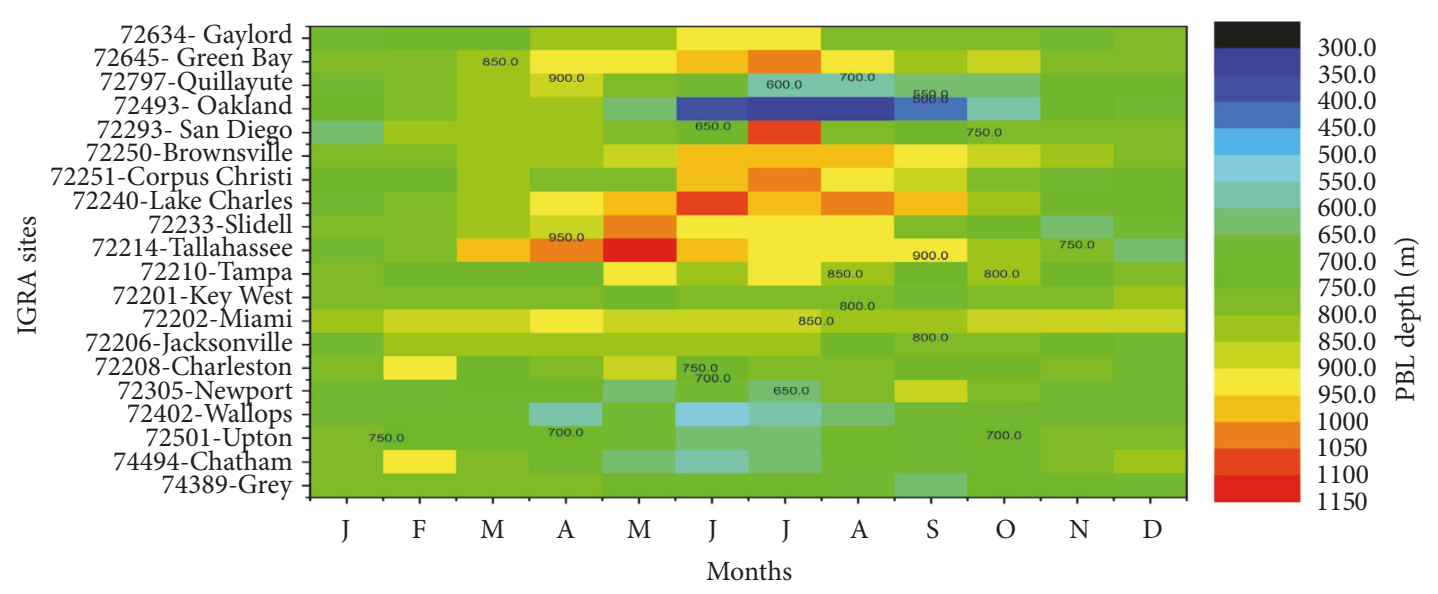

FIGURE 9: Seasonal cycles of median PBL depths at 20 IGRA sites which are located along or near the coastline. Both the IGRA station identifications and the locations of the 20 IGRA sites are indicated on the $y$-axis and are organized according to their distances from the nearest coastline. For the PBL depth contour, a color bar scale limit (between 300 and $1200 \mathrm{~m}$ ) was chosen to represent all the available climatological monthly median values of PBL depths at those 20 sites. Stations are sorted by distance from the coast; thus, Grey is nearest the coast, whereas Gaylord is furthest from the coast.

TX, showing the largest PBL depths (around $1500 \mathrm{~m}$ ) during these months. The largest PBL depths during the summer months over Fort Worth, TX (which is the 16th largest city in the US and the 5th largest city in Texas), are attributed to the impact of significant urbanization in the Dallas-Fort Worth metropolitan area compared to other sites in the Cfa climate region. Significant urbanization over this site results in higher temperatures and larger partitioning of available energy into sensible heating, producing the larger PBL depths over this site compared to the other, less urbanized sites within the Cfa climate region. The occurrence of larger PBL depths over cities is well-known and has been reported in many previous studies [38-40]. As presented in Figure 11 for climate type Cfa, similar analyses were also performed for the PBL depth variability for the other key climatic regions of the contiguous US (i.e., Dfa, BSk, Dfb, Dsb, and BWK) and corresponding results are shown in Figure 12. For brevity, we have presented only the box-and-whisker analyses.

As with climate type Cfa, there is also much similarity among the stations with climate type Dfa (Figure 12(a)), which is associated with a cold climate, no dry season, and warm summer. At sites with climate type Dfa, PBL depths 


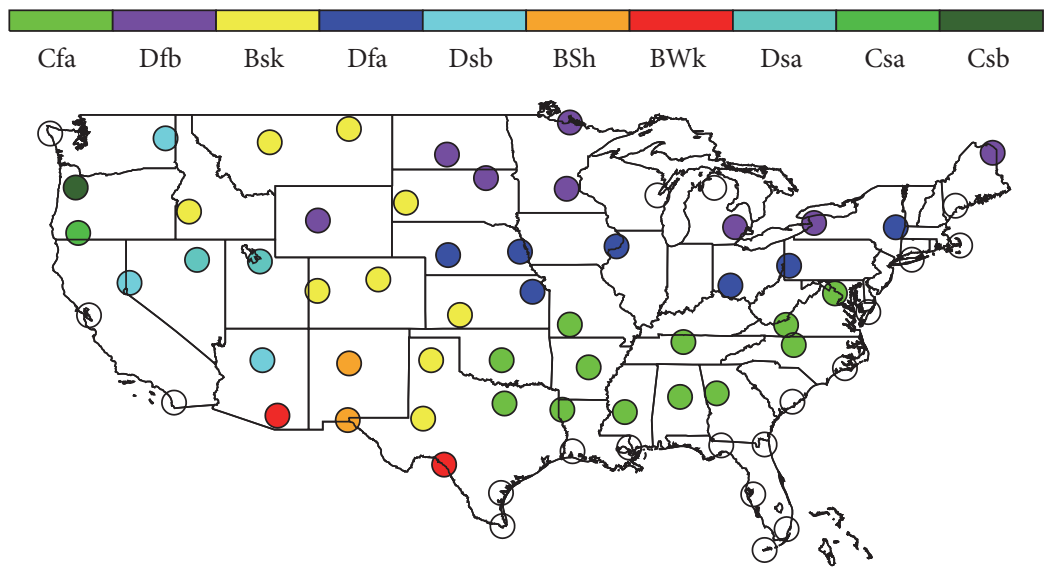

FIGURE 10: Köppen-Geiger climate classification, adopted from [24]. Open circles denote IGRA station locations while the color bar on the top denotes different climate classes. The number of IGRA rawinsonde sites (omitting coastal sites) as a function of Köppen-Geiger climate classification varies as Cfa: 12; Dfb: 8; BSk: 9; Dfa: 7; Dsb: 3; BSh: 2; BWk: 2; Dsa: 2; Csa; and Csb: 1. Climate types are not shown for coastal sites.

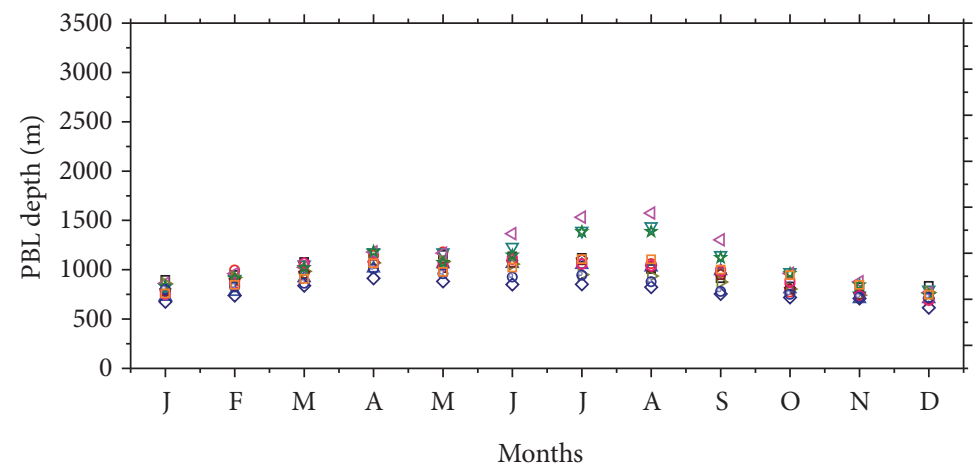
72215
$\Delta 72235$
$\triangleleft 72249$
$\diamond 72318$
- 72340
- 72403
- 72230
$\nabla 72248$
$\triangleright 72317$
- 72327
म 72357
72440

(a)

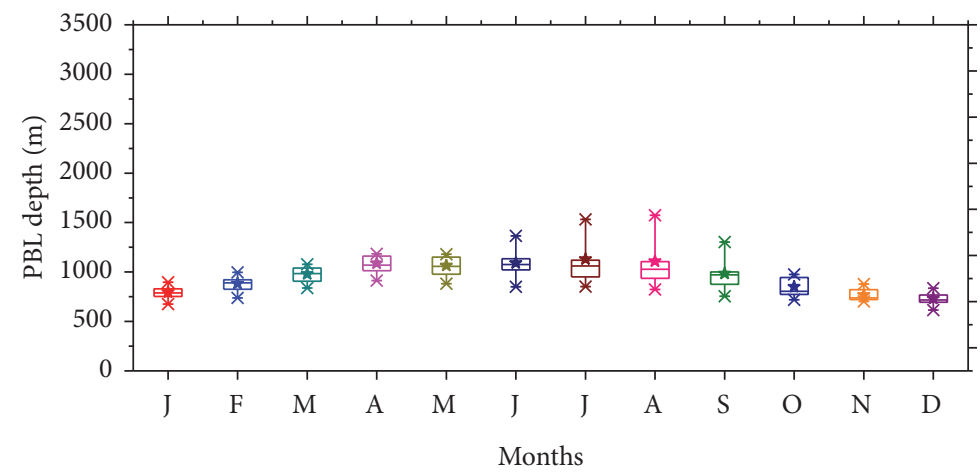

(b)

FIGURE 11: Climatological mean and median PBL depth seasonal cycles over the Cfa climate type sites illustrating variability in PBL depths during different months (a). Different symbols mark climatological monthly mean and median PBL depths over 12 IGRA sites shown in Table 1. Box-and-whisker analyses of the site-to-site PBL depth variability over Cfa type climatic region (b) based on the results shown in panel (a). 


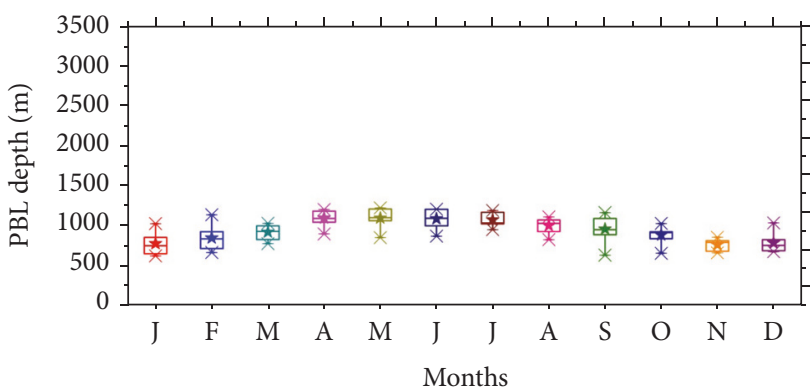

(a) $\operatorname{Dfa}(N=7)$

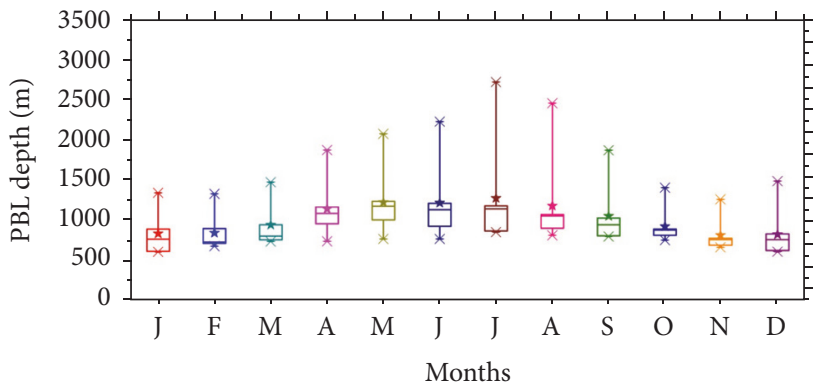

(c) $\operatorname{Dfb}(N=8)$

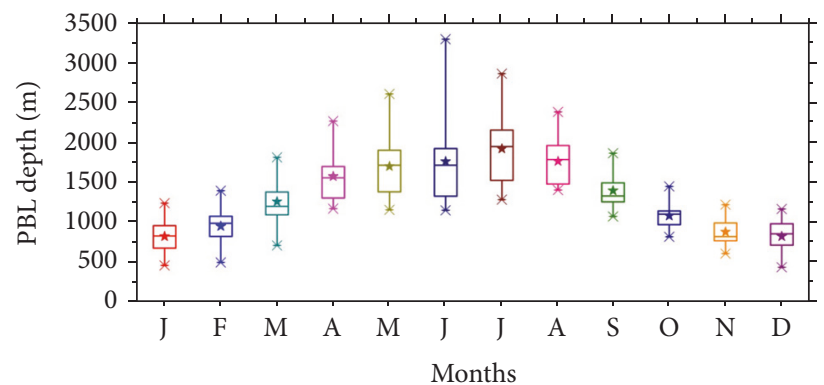

(b) $\operatorname{BSk}(N=9)$

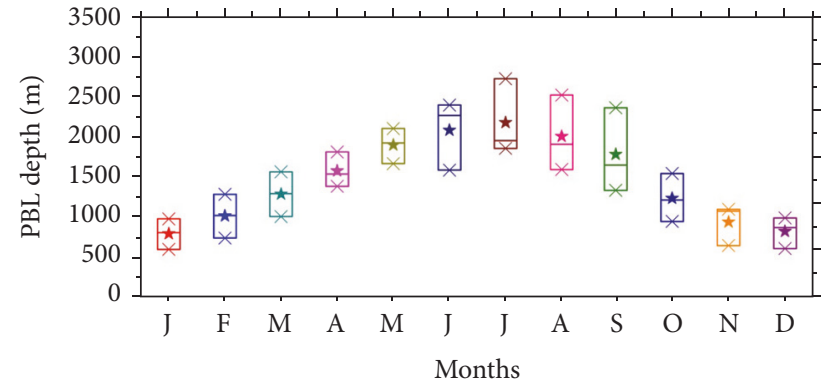

(d) $\operatorname{Dsb}(N=3)$

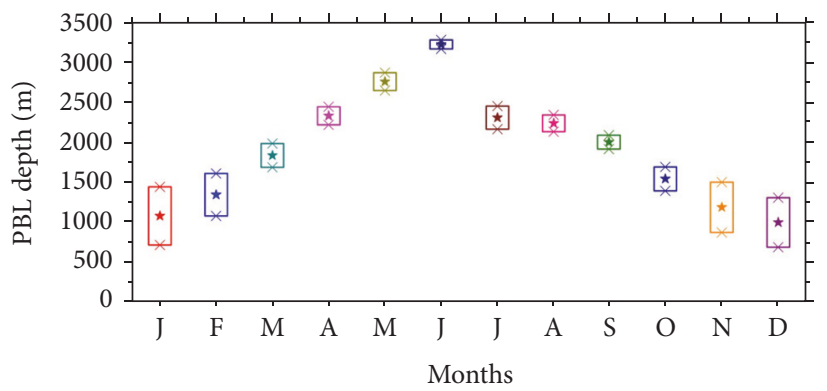

(e) $\operatorname{BWk}(N=2)$

Figure 12: Box-and-whisker analyses of the site-to-site PBL depth variability over the region classified as Dfa (a), BSk (b), Dfb (c), Dsb (d), and BWk (e). On each panel, climate type and number of IGRA sites for each category are also marked (see $N$ values in the parentheses). Similar $y$-axis scale limits were used for comparison among the different climate types.

are lowest in January, and there is a broad maximum between April and September.

Although climate type Dfa is very similar to climate type $\mathrm{Dfb}$, with Dfb characterized by a cold climate overall, no dry season but hot summers, there is large variability in PBL depths in the different months for stations with climate type Dfb (Figure 12(c)) which is driven by the PBL depth climatology at Riverton, WY (Wyoming), in the west and at Caribou, ME, in the east. Thus, large differences in geographical location, land surface features surrounding the station, and corresponding difference between local time cannot be ignored.

For example, at Riverton, mean and median PBL depths range from around $1400 \mathrm{~m}$ in January to a maximum around $2700 \mathrm{~m}$ in July. The larger PBL depths at this station compared with the others in this climate type are because the Riverton, WY station, is located within the central Rocky Mountains and is much more susceptible to the effects of orography and arid conditions, both of which result in much deeper PBLs than other stations located within this particular climate type. Similarly, Grand Junction, CO, which has climate type BSk that is characterized by a cold, arid, steppe climate, is located in the Rocky Mountains, and is subject to similar local-scale effects as Riverton, WY. These local to regional scale topographical effects result in Grand Junction, CO, having the largest PBL depths between April and August of all stations with the BSk climate type (Figure 12(b)).

The three stations with climate type Dsb, characterized by cold and dry conditions with a warm summer, are all located in the western US and immune from coastal influences. These stations (Flagstaff, AZ; Reno, NV (Nevada); and Spokane, Washington) have similar behavior in the month-to-month changes in PBL depth (Figure 12(e)), although Reno, NV, typically has the deepest PBL depths because it has the driest climate of these three stations. Additionally, all sites with climate type Dsb are located within mountainous regions of the 


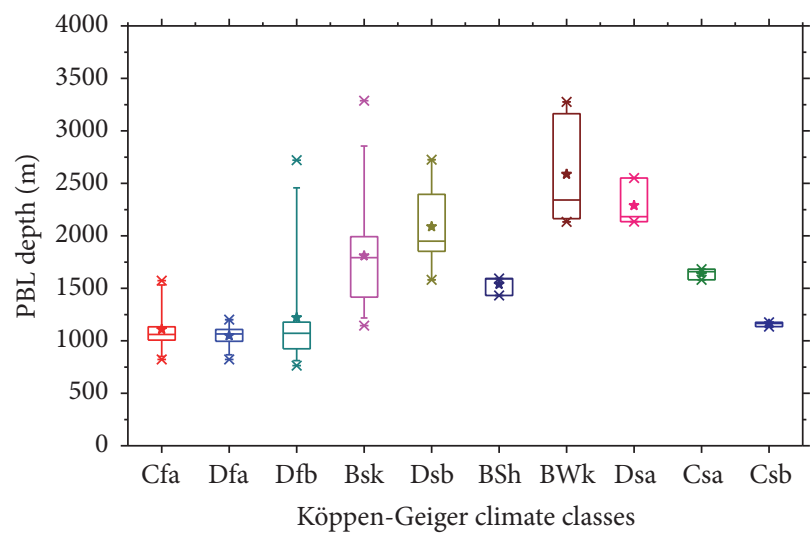

(a) Summer

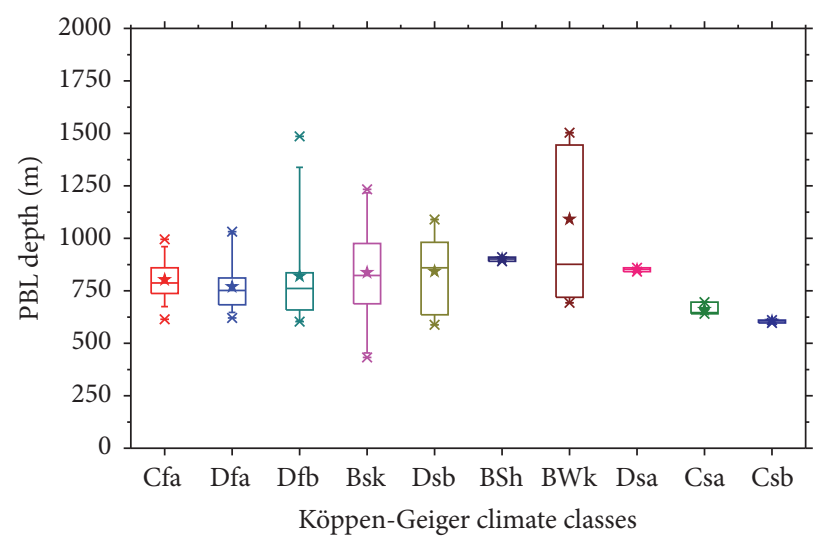

(b) Winter

FIGURE 13: Box-and-whisker analyses of the climatological averages of summer (a) and winter (b) PBL depths aggregated by climate class. Two different maximum $y$-axis scale limits were used for summer (4000 m, panel (a)) and winter (2000 m, panel (b)) seasons to illustrate PBL depth variability within a given season. All the available summer and winter monthly mean values of PBL depths over the sites located within each climatic region are considered.

western US and thus are most susceptible to terrain-induced interactions on PBL depths [31] than stations located in flat terrain.

The final climate type, BWk, characterized by a dry, cold, and desert climate, includes the two stations located in New Mexico (Santa Teresa and Albuquerque) (cf. Figure 1 and Table 1). Maximum PBL depths are observed in June, where median PBL depths exceed $3000 \mathrm{~m}$ at both sites (Figure 12(e)). Following the maximum in June, median PBL depths on average decrease during the mid to late summer because of the monsoonal transport of moisture. To the best of our knowledge, these results are the first of their kind and provide important insights on the spatial variability of the climatological mean PBL depth variability for different climate regimes and geographical locations of the contiguous US.

3.6. Overall Climatological Patterns of Summer and Winter $P B L$ Depths by Climate Types. Finally, we summarize the overall climatological mean and medians of summer and winter PBL depths for the 10 climate types based on the 25 years of measurements so that general characteristics of the PBL depths can be revealed. The aim of these analyses is to illustrate the most significant differences of PBL depths in two extreme seasons (summer and winter) based on the median seasonal cycles in PBL depths discussed in the previous sections. Results presented in Figures 11 and 12 were used to compute the median and mean summer and winter PBL depths for the representative climate types (Figure 13). We first determined the seasonal mean values (here, summer and winter) for a particular station within a climatic region (e.g., $\mathrm{Cfa}$ ) and averaged those mean values to obtain summer and winter averages for that climatic region so that the variability observed for a particular climatic region is due to the spatial variability of PBL depths at different sites within a given climatic region.
Summer PBL depths are largest in regions with climate type BWk and Dsa, where mean PBL depths over these regions are around $2500 \mathrm{~m}$ and $2300 \mathrm{~m}$, respectively (Figure 13(a)). The lowest summertime PBL depths are observed at regions with climate types $\mathrm{Cfa}, \mathrm{Dfa}$, and Csa, where median PBL depths are between 1000 and $1200 \mathrm{~m}$. During winter, PBL depths are more similar than during the summer among the different climate regimes (Figure 13(b)). As with during the summer, during the winter the largest PBL depths occur in regions with climate type $\mathrm{BWk}$, where mean PBL depths are about $1100 \mathrm{~m}$. These results also confirm that the maximum summer and winter PBL depth variability occurs for the sites located in the region characterized by climate type BWK.

In the other climate types, median PBL depths during the winter range from $625 \mathrm{~m}$ to $875 \mathrm{~m}$ over climate type Csb and BSh, respectively. When considering the amount of PBL depth spatial variability within each climate class, it is found that $\mathrm{PBL}$ depth variability is highest for regions designated by climate types Dfb and BSk covering wide east to west and north to south US sectors, respectively. This feature also holds true for winter PBL depth variability. We also note large differences for the two sites with climate type BWk, which may be attributed to terrain-induced interactions on PBL depths [31] at these sites.

Additionally, both the summer and the winter PBL depth variability for the regions classified by climate types Csa and Csb cannot be determined as only one site for each of these climate types is available as shown in Figure 10. Therefore, the very small PBL depth variability shown in Figure 13 for these climate types is mainly related to interannual variability in PBL depths in both seasons.

Overall, the results in this study provide new insights into the spatiotemporal variability of the depth of the quasistationary afternoon PBL, estimated by applying a new technique to rawinsonde observations from 0000 UTC over the contiguous US. It is important to note, though, some of 
the limitations associated with using this technique and how these limitations impact the results. One limitation of this technique is that it neglects the role of subsidence when estimating afternoon PBL depths. Previous studies have shown that subsidence can lead to decreases in PBL depths during the afternoon about $200 \mathrm{~m}$ [41] which would have the largest impact over locations where 0000 UTC is at 1900 LST, that is, areas where there is the largest difference in time between the midafternoon and the time when the sounding is made locally.

Another potential limitation of the technique implemented in the present study is that the technique may overestimate PBL depths for locations where there are very shallow near-surface inversions that are not caused by radiational cooling at, for example, coastal sites. However, the geographic distribution of low-level inversion frequency (cf. Figure 3(a)) shows that shallow near-surface inversions are uncommon at coastal sites and instead increases west to east because of the local time when the soundings are made.

Despite these limitations, the present study eliminates a known uncertainty arising when comparing soundingderived PBL depths over the eastern US with those over the western US [6] and produces meaningful insights on the spatiotemporal variability in afternoon PBL depths over different geographic and climatic regions of the contiguous US.

\section{Summary, Conclusions, and Outlook}

In summary, we applied a recently developed technique [25] to compute the depth of the afternoon quasistationary PBL from 516,887 rawinsonde profiles over the contiguous US for the 25-year period between 1991 and 2015 from 67 sites in the United States. Consequently, we used these results to develop a climatology of afternoon PBL depths as a function of US region and Köppen-Geiger climate regime. We found that, with the removal of the near-surface stable layer from 0000 UTC rawinsonde observations, afternoon PBL depths have the largest seasonal variability over the arid southwestern US and Southern Great Plains. In contrast, the continental sites in the Upper Midwest and Northeast show the smallest seasonal variability in PBL depths.

Results pertaining to the overall climatological medians of both summer and spring PBL depths reveal a strong east to west PBL depth gradient in the continental US with higher PBL depths over the western states ( 1500-1800 m in spring and $\sim 2000 \mathrm{~m}$ in summer) than over the eastern states (between 800 and $1200 \mathrm{~m}$ in both spring and summer) due to the enhanced topography and aridity in the western side of the country. The east to west PBL depth contrast is more prominent during the summer months than during the spring, whereas it remains negligible in winter months (i.e., gradients on the order of $100 \mathrm{~m}$ in PBL depths per $1000 \mathrm{~km}$, cf. Figure 4(a)). We also found strong seasonal contrasts in PBL depths that occur over the desert and other semiarid regions, especially along the western side of the Rocky Mountains.

Additionally, sites located in close proximity to the coast and Great Lakes did not exhibit a prominent seasonal cycle in features due to the influence of the marine boundary layer. Furthermore, several coastal sites had much shallower PBL depths during the summer than during the winter, and the PBL depths exhibited little or no substantial seasonal variability.

When we classified the stations by Köppen-Geiger climate type, we found that the BWk (arid, desert, and cold) climate type has the largest median winter and summer PBL depths, with values around $875 \mathrm{~m}$ and $2500 \mathrm{~m}$, respectively. In contrast, median PBL depths for Cfa (temperate, without dry season, and hot summer), Dfa (cold, without dry season, and warm summer), and Dfb (cold, without dry season, and hot summer) climate types are around $750 \mathrm{~m}$ and $1000 \mathrm{~m}$ during the winter and summer, respectively.

This study builds upon other, previously discussed, studies of PBL depth climatologies conducted over North America and Europe that were obtained from rawinsonde observations [6,23], wind profilers [12], and spaceborne lidar [17] by determining the spatiotemporal variability in afternoon estimates of PBL depth over different regions and climate classifications of the contiguous US. The application of the technique employed in the present study has shown great utility for the contiguous US and is expected to have similar utility over other regions, for example, eastern Asia where the 1200 UTC sounding is in early evening local time, for studies on the spatiotemporal variability in the depth of the quasistationary afternoon PBL.

In future studies, we will utilize North American Regional Reanalysis (NARR) derived meteorological fields to further investigate PBL depth features over different geographical locations of the contiguous US and climate types. The extent to which NARR can simulate the features of PBL depth seasonal cycles over different sites characterized by various climate types observed in Figures 11 and 12 will provide new findings on the skill of reanalysis products. Thus, it will be possible to address in detail the effects of changes in land surface forcing over diverse geographical regions, as was recently performed by [42] for Europe using Transport Model 5 (TM5). Also, the analyses will be extended for the $>200$ IGRA sites located along coasts around the world to further investigate the impact of marine boundary layer features on PBL depths at coastal locations.

\section{Disclosure}

Temple R. Lee and Sandip Pal performed the work as part of their independent research for career development.

\section{Conflicts of Interest}

The authors declare that there are no conflicts of interest regarding the publication of this paper.

\section{Acknowledgments}

The IGRA rawinsonde data sets were obtained from $\mathrm{ftp}: / / \mathrm{ftp}$.ncdc.noaa.gov/, and the Köppen-Geiger climate types were obtained from $<$ http://koeppen-geiger.vu-wien.ac .at/present.htm>. Satellite imagery from Google Earth Inc. was used to help generate Figure 5. 


\section{References}

[1] R. B. Stull, An Introduction to Boundary Layer Meteorology, Kluwer Academic Publishers, 1988.

[2] W. F. Dabberdt, M. A. Carroll, D. Baumgardner et al., "Meteorological research needs for improved air quality forecasting: report of the 11th prospectus development team of the U.S. Weather Research Program," Bulletin of the American Meteorological Society, vol. 85, no. 4, pp. 563-586, 2004.

[3] T. R. Lee, S. F. J. de Wekker, S. Pal, A. E. Andrews, and J. Kofler, "Meteorological controls on the diurnal variability of carbon monoxide mixing ratio at a mountaintop monitoring site in the Appalachian Mountains," Tellus, Series B: Chemical and Physical Meteorology, vol. 67, no. 1, Article ID 25659, 2015.

[4] A. Behrendt, V. Wulfmeyer, E. Hammann, S. K. Muppa, and S. $\mathrm{Pal}$, "Profiles of second- to fourth-order moments of turbulent temperature fluctuations in the convective boundary layer: first measurements with rotational Raman lidar," Atmospheric Chemistry and Physics, vol. 15, no. 10, pp. 5485-5500, 2015.

[5] A. Behrendt, G. Wagner, A. Petrova et al., "Modular lidar systems for high-resolution 4-dimensional measurements of water vapor, temperature, and aerosols," in Lidar Remote Sensing for Industry and Environmental Monitoring V, U. N. Singh and K. Mizutani, Eds., vol. 5653 of Proceedings of SPIE, pp. 220-227, Honolulu, Hawaii, USA, November 2004.

[6] D. J. Seidel, Y. Zhang, A. Beljaars, J.-C. Golaz, A. R. Jacobson, and B. Medeiros, "Climatology of the planetary boundary layer over the continental United States and Europe," Journal of Geophysical Research Atmospheres, vol. 117, no. 17, Article ID D17106, 2012.

[7] J. Guo, Y. Miao, Y. Zhang et al., "The climatology of planetary boundary layer height in China derived from radiosonde and reanalysis data," Atmospheric Chemistry and Physics, vol. 16, no. 20, pp. 13309-13319, 2016.

[8] D. J. Seidel, C. O. Ao, and K. Li, "Estimating climatological planetary boundary layer heights from radiosonde observations: comparison of methods and uncertainty analysis," Journal of Geophysical Research: Atmospheres, vol. 115, no. 16, Article ID D16113, 2010.

[9] F. Beyrich, U. Weisensee, D. Sprung, and H. Güsten, "Comparative analysis of sodar and ozone profile measurements in a complex structured boundary layer and implications for mixing height estimation," Boundary-Layer Meteorology, vol. 81, no. 1, pp. 1-9, 1996.

[10] R. San José and J. Casanova, "An empirical method to evaluate the height of the convective boundary layer by using small mast measurements," Atmospheric Research, vol. 22, no. 3, pp. 265$273,1988$.

[11] C. E. Yver, H. D. Graven, D. D. Lucas, P. J. Cameron-Smith, R. F. Keeling, and R. F. Weiss, "Evaluating transport in the WRF model along the California coast," Atmospheric Chemistry and Physics, vol. 13, no. 4, pp. 1837-1852, 2013.

[12] L. Bianco, I. V. Djalalova, C. W. King, and J. M. Wilczak, "Diurnal evolution and annual variability of boundary-layer height and its correlation to other meteorological variables in California's Central Valley," Boundary-Layer Meteorology, vol. 140, no. 3, pp. 491-511, 2011.

[13] S. F. Clifford, R. J. Lataitis, J. C. Kaimal, and R. G. Strauch, "Ground-based remote profiling in atmospheric studies: an overview," Proceedings of the IEEE, vol. 82, no. 3, pp. 313-355, 1994.
[14] S. Pal, M. Haeffelin, and E. Batchvarova, "Exploring a geophysical process-based attribution technique for the determination of the atmospheric boundary layer depth using aerosol lidar and near-surface meteorological measurements," Journal of Geophysical Research Atmospheres, vol. 118, no. 16, pp. 92779295, 2013.

[15] P. Seibert, F. Beyrich, S. E. Gryning, S. Joffre, A. Rasmussen, and P. Tercier, "Mixing layer depth determination for dispersion modelling, European Commission," in COST Action 710-Final Report, Harmonisation of the Pre-Processing of Meteorological Data for Atmospheric Dispersion Models L-2985, B. E. A. Fisher, J. J. Erbrink, S. Finardi et al., Eds., Luxembourg European Commission, 1998.

[16] F. Beyrich, "Mixing height estimation from sodar data-a critical discussion," Atmospheric Environment, vol. 31, no. 23, pp. 3941-3953, 1997.

[17] E. L. McGrath-Spangler and A. S. Denning, "Estimates of North American summertime planetary boundary layer depths derived from space-borne lidar," Journal of Geophysical Research: Atmospheres, vol. 117, no. 15, Article ID D15101, 2012.

[18] D. M. Winker, W. H. Hunt, and M. J. McGill, "Initial performance assessment of CALIOP," Geophysical Research Letters, vol. 34, no. 19, Article ID L19803, 2007.

[19] W. Zhang, J. Guo, Y. Miao et al., "Planetary boundary layer height from CALIOP compared to radiosonde over China," Atmospheric Chemistry and Physics, vol. 16, no. 15, pp. 99519963, 2016.

[20] S. Liu and X.-Z. Liang, "Observed diurnal cycle climatology of planetary boundary layer height," Journal of Climate, vol. 23, no. 21, pp. 5790-5809, 2010.

[21] X. Y. Wang and K. C. Wang, "Estimation of atmospheric mixing layer height from radiosonde data," Atmospheric Measurement Techniques, vol. 7, no. 6, pp. 1701-1709, 2014.

[22] Y. Zhang, D. J. Seidel, and S. Zhang, "Trends in planetary boundary layer height over europe," Journal of Climate, vol. 26, no. 24, pp. 10071-10076, 2013.

[23] P. Seibert, F. Beyrich, S.-E. Gryning, S. Joffre, A. Rasmussen, and P. Tercier, "Review and intercomparison of operational methods for the determination of the mixing height," Atmospheric Environment, vol. 34, no. 7, pp. 1001-1027, 2000.

[24] M. Kottek, J. Grieser, C. Beck, B. Rudolf, and F. Rubel, "World map of the Köppen-Geiger climate classification updated," Meteorologische Zeitschrift, vol. 15, no. 3, pp. 259-263, 2006.

[25] T. R. Lee and S. F. J. De Wekker, "Estimating daytime planetary boundary layer heights over a valley from rawinsonde observations at a nearby airport: an application to the page valley in Virginia, United States," Journal of Applied Meteorology and Climatology, vol. 55, no. 3, pp. 791-809, 2016.

[26] E. L. McGrath-Spangler and A. Molod, "Comparison of GEOS5 AGCM planetary boundary layer depths computed with various definitions," Atmospheric Chemistry and Physics, vol. 14, no. 13, pp. 6717-6727, 2014.

[27] I. Durre and X. Yin, "Enhanced radiosonde data for studies of vertical structure," Bulletin of the American Meteorological Society, vol. 89, no. 9, pp. 1257-1261, 2008.

[28] L. Wang and M. A. Geller, "Morphology of gravity-wave energy as observed from 4 years (1998-2001) of high vertical resolution U.S. radiosonde data," Journal of Geophysical Research D: Atmospheres, vol. 108, no. 16, 2003.

[29] D. M. Hondula, R. E. Davis, D. B. Knight et al., "A respiratory alert model for the Shenandoah Valley, Virginia, USA," International Journal of Biometeorology, vol. 57, no. 1, pp. 91-105, 2013. 
[30] S. Pal, S. F. De Wekker, and G. D. Emmitt, "Investigation of the spatial variability of the convective boundary layer heights over an isolated mountain: cases from the MATERHORN-2012 experiment," Journal of Applied Meteorology and Climatology, vol. 55, no. 9, pp. 1927-1952, 2016.

[31] D. R. Bright and S. L. Mullen, "The sensitivity of the numerical simulation of the southwest monsoon boundary layer to the choice of PBL turbulence parameterization in MM5," Weather and Forecasting, vol. 17, no. 1, pp. 99-114, 2002.

[32] S. F. J. De Wekker and M. Kossmann, "Convective boundary layer heights over mountainous terrain-a review of concepts," Frontiers in Earth Science, vol. 3, article 77, 2015.

[33] M. W. Rotach and D. Zardi, "On the boundary-layer structure over highly complex terrain: key findings from MAP," Quarterly Journal of the Royal Meteorological Society, vol. 133, no. 625, pp. 937-948, 2007.

[34] B. Medeiros, A. Hall, and B. Stevens, "What controls the mean depth of the PBL?” Journal of Climate, vol. 18, no. 16, pp. 31573172, 2005.

[35] E. L. Mcgrath-Spangler and A. S. Denning, "Impact of entrainment from overshooting thermals on land-atmosphere interactions during summer 1999," Tellus, Series B: Chemical and Physical Meteorology, vol. 62, no. 5, pp. 441-454, 2010.

[36] K. M. Chan and R. Wood, "The seasonal cycle of planetary boundary layer depth determined using COSMIC radio occultation data," Journal of Geophysical Research Atmospheres, vol. 118, no. 22, pp. 12422-12434, 2013.

[37] M. C. Peel, B. L. Finlayson, and T. A. McMahon, "Updated world map of the Köppen-Geiger climate classification," Hydrology and Earth System Sciences, vol. 11, no. 5, pp. 1633-1644, 2007.

[38] T. R. Oke, "The energetic basis of the urban heat island," Quarterly Journal of the Royal Meteorological Society, vol. 108, no. 455, pp. 1-24, 1982.

[39] C.-Y. Lin, F. Chen, J. C. Huang et al., "Urban heat island effect and its impact on boundary layer development and land-sea circulation over northern Taiwan," Atmospheric Environment, vol. 42, no. 22, pp. 5635-5649, 2008.

[40] S. Pal, I. Xueref-Remy, L. Ammoura et al., "Spatio-temporal variability of the atmospheric boundary layer depth over the Paris agglomeration: an assessment of the impact of the urban heat island intensity," Atmospheric Environment, vol. 63, pp. 261275, 2012.

[41] E. Blay-Carreras, D. Pino, J. Vilà-Guerau De Arellano et al., "Role of the residual layer and large-scale subsidence on the development and evolution of the convective boundary layer," Atmospheric Chemistry and Physics, vol. 14, no. 9, pp. 4515-4530, 2014.

[42] E. N. Koffi, P. Bergamaschi, U. Karstens et al., "Evaluation of the boundary layer dynamics of the TM5 model over Europe," Geoscientific Model Development, vol. 9, no. 9, pp. 3137-3160, 2016. 

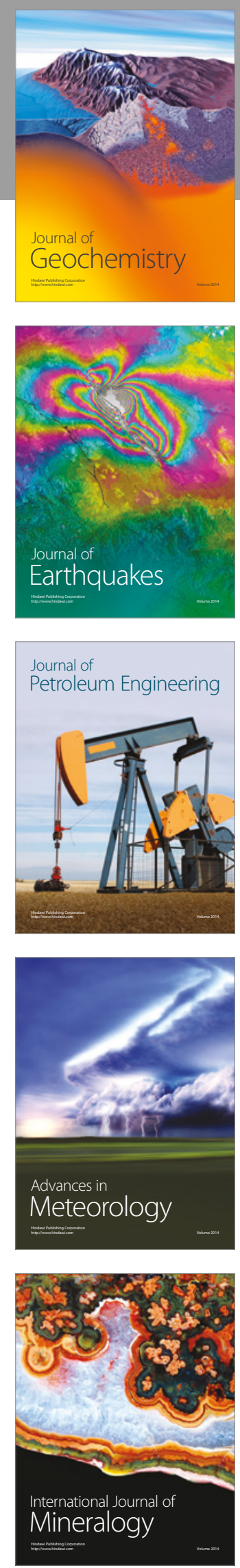
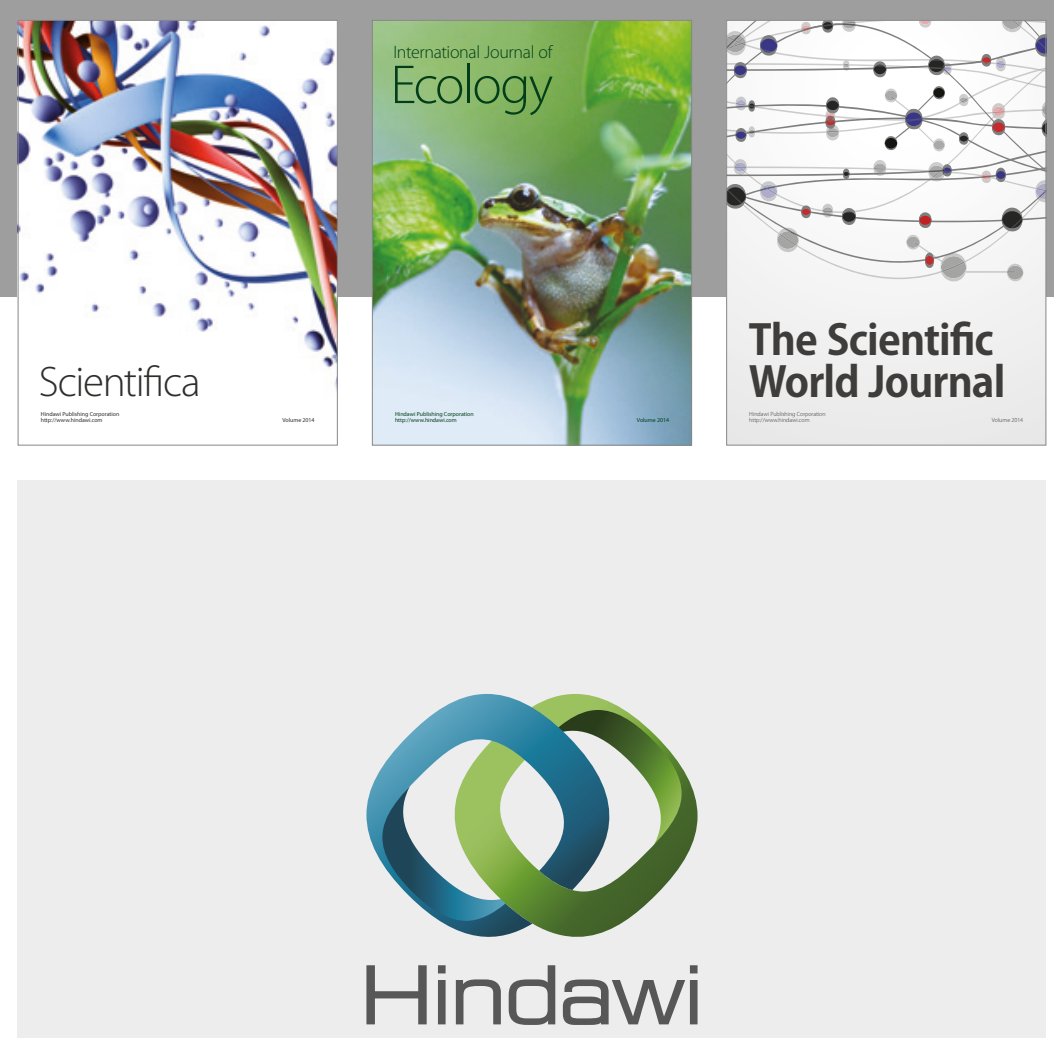

Submit your manuscripts at

https://www.hindawi.com
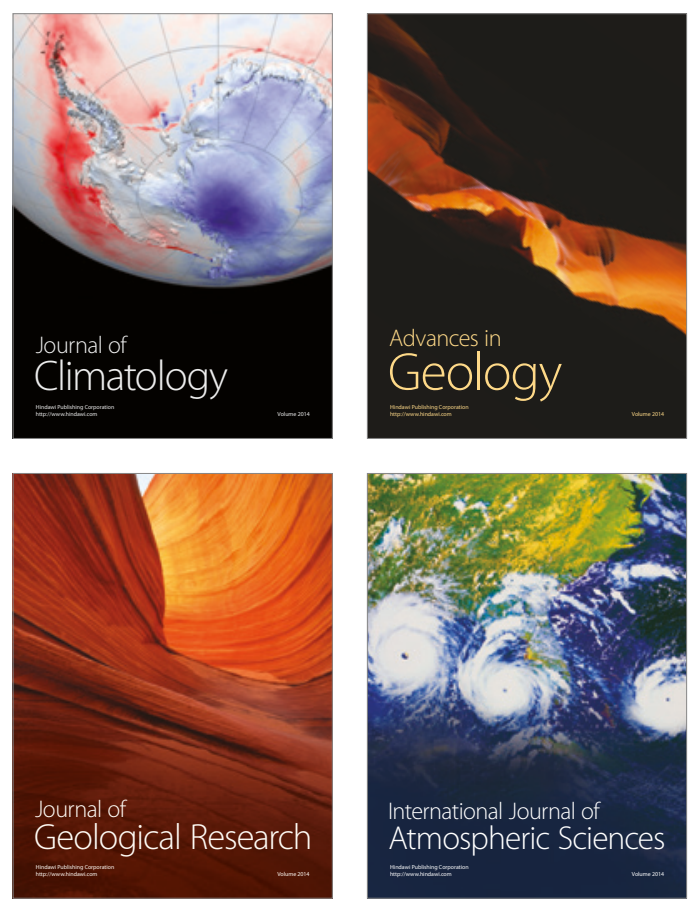

The Scientific

World Journal
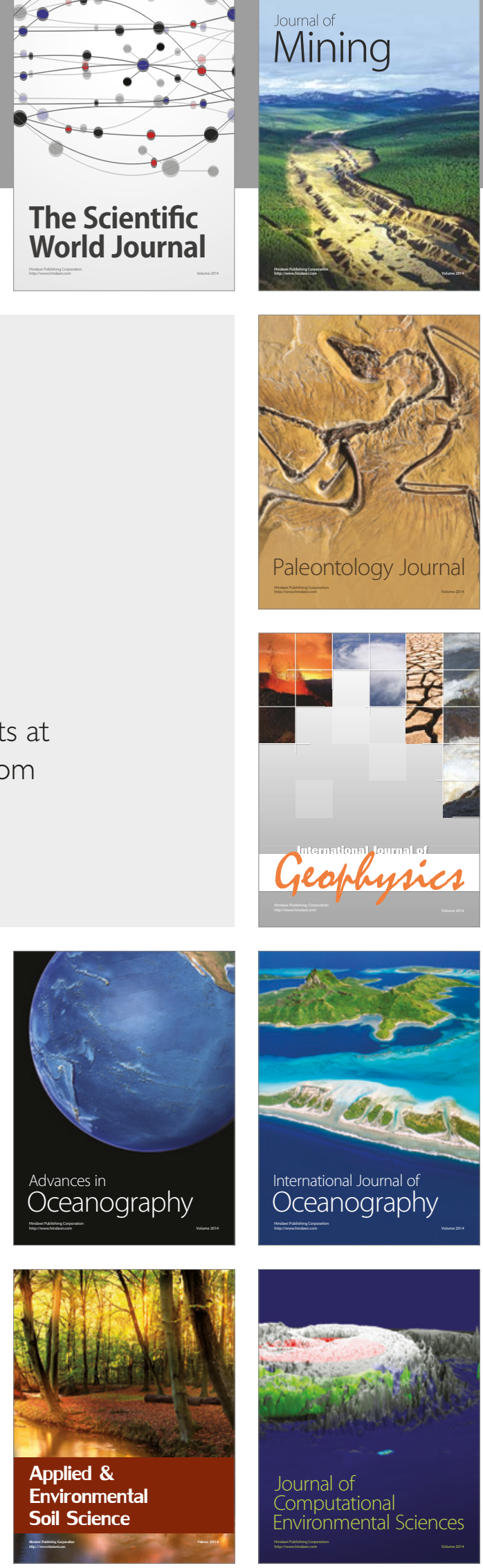